\title{
New taxa of crickets (Orthoptera: Grylloidea: Phaloriinae, Phalangopsinae, Itarinae and Podoscirtinae) from Borneo (Brunei Darussalam and Sandakan)
}

Running title: New crickets from Borneo

\author{
MING KAI TAN ${ }^{1 *}$, RAZY JAPIR ${ }^{2}$, ARTHUR Y. C. CHUNG ${ }^{2} \&$ RODZAY BIN HAJI ABDUL \\ WAHAB $^{3}$ \\ ${ }^{1}$ Institut de Systématique, Evolution et Biodiversité, Muséum national d'Histoire naturelle, CNRS, \\ SU, EPHE, UA, 57 rue Cuvier, CP 50, 75231 Paris Cedex 05, France \\ ${ }^{2}$ Forest Research Centre (Sepilok), Sabah Forestry Department, P.O. Box 1407, 90715 Sandakan, \\ Sabah. \\ ${ }^{3}$ Institute for Biodiversity and Environmental Research, Universiti Brunei Darussalam, Jalan \\ Universiti, BE1410, Brunei Darussalam \\ *Corresponding author: orthoptera.mingkai@gmail.com
}

\begin{abstract}
Three new species were described from Borneo: Itara (Bornitara) cuspis sp. nov. and Aphonoides duri sp. nov. from Brunei and Varitrella (Cantotrella) suikei sp. nov. from Sandakan in Sabah. We describe the call of Varitrella (Cantotrella) suikei sp. nov. In addition to the new species descriptions, we also report new locality records of other recently discovered species: Borneloria cuspis Gorochov, 2018 in Belait (Brunei Darussalam), species of Anemozara Gorochov, 2014 in Brunei Darussalam and Terrozacla borneo Gorochov, 2014 in Belait.
\end{abstract}

Key words: Aphonoidini, Podoscirtini, new species, Southeast Asia

\section{Introduction}

Borneo is one of the most biodiverse regions, but the curve for new species discovery of orthopterans has not flattened (Tan et al., 2017). This is likely to be true for the gryllids, in which new genera are still being discovered from Borneo not long ago (e.g., Gorochov, 2018). Very recently, a new species of Lebinthus Stål, 1877 was discovered from Sandakan in Sabah, representing the first species of this relatively well studied genus to be described from Borneo (Tan et al., 2019a). Given that Lebinthus can be speciose in other parts of its distribution, i.e., the Philippines (Baroga-Barbecho et al., 2020, unpublished), it is not surprising more species will be uncovered from Borneo. A new species of Mimicogryllus was described from Brunei Darussalam, representing the first record of this genus (comprising of two other species) outside Indochina (Tan et al., 2019b). The genus Tembelingiola Gorochov, 2004 was also first discovered in Borneo from recent surveys (Tan et al., 2019b). These illustrate that we are still very far from knowing well the orthopteran diversity in Borneo and the distributions of Southeast Asian species.

Continued samplings of Brunei Darussalam and Sandakan (in Sabah) led to further discovery of poorly known crickets. Here, we describe three new species: Itara (Bornitara) cuspis sp. nov. and Aphonoides duri sp. nov. from Brunei and Varitrella (Cantotrella) suikei sp. nov. from Sandakan. In addition to the new species descriptions, we also report new locality records of other recently discovered species.

\section{Materials and methods}

Sampling. Field collections and observations were made in two districts of Brunei Darussalam: (1) Belait: Andulau Forest Reserve, Wasai Wong Kadir Recreational Park and Jalan Labi at Teraja between 23 February and 3 March 2019 and between 6 and 9 July 2019; and (2) Temburong: Kuala Belalong Field Studies Centre between 11 to 17 July 2019 (Tan et al., 2019b: Fig. 1). Surveys were 
also conducted at the Rainforest Discovery Centre (Sandakan, Sabah) between 8 and 12 January 2019. Specimens were collected by sight during, night and day. Whenever possible, in-situ images were taken using a Canon EOS 500D digital SLR camera with a compact-macro lens EF $100 \mathrm{~mm} \mathrm{f} / 2.8$ Macro USM and Canon Macro Twin Lite MT-24EX was used for lighting and flash.

Acoustic recording and analyses. The basic cricket song terminology follows Ragge \& Reynolds (1998). One song unit is called a syllable and corresponds to one opening-closure cycle of the male forewings. A group of syllables constitutes an echeme, which corresponds to a call unit in terms of communication. The recordings of Varitrella (Cantotrella) suikei sp. nov. were made using a sampling frequency of $256 \mathrm{kHz}$-samples/s Echo Meter Touch (based on Knowles FG sensor) in the field station. Song features were measured using Avisoft Lite 2.0.0 (Cornell Lab of Ornithology Bioacoustics Research Program). Power spectra using FFT were generated using the 'spec' function at 256,000 sampling frequency, using Hanning window of window length 512 in the R package seewave (Sueur et al., 2008) in the R software version 3.5.1 (R Development Core Team, 2018).

Curation and examination of materials. The specimens were preserved in absolute analytical-grade ethanol and later pinned and dry-preserved. A single hind leg from each specimen was also preserved in absolute analytical-grade ethanol for future molecular work. Male genitalia were dissected from softened specimens and removed by squeezing the cerci against one another laterally. The male genitalia were then cleaned using aqueous $\mathrm{KOH}$ and subsequently preserved in glycerine. Terminology used to describe the male genitalia follows Gorochov \& Tan (2014) and Gorochov (2015).

Habitus images were made with a Canon EOS 500D digital SLR camera with a compact-macro lens EF $100 \mathrm{~mm} \mathrm{f} / 2.8$ Macro USM. Close-up images of morphological features (including male genitalia) were done using a Canon EOS 500D digital SLR camera with a macro photo lens MP-E $65 \mathrm{~mm} \mathrm{f} / 2.8$ USM (1-5×). Canon Macro Twin Lite MT-24EX was used for lighting and flash. Images of male genitalia were also done using a Samsung Galaxy A70 phone camera attached to a Meiji EMZ stereozoom microscope. Image editing was accomplished using Adobe Photoshop CC 2014 (Adobe Systems Incorporated, San Jose, CA, USA).

Measurements of dried-pinned specimen were made using ImageJ 1.51j8 (Wayne Rasband, Research Services Branch, National Institute of Mental Health, Bethesda, MD, USA). In the measurements, the following abbreviations are used: $\mathrm{BL}=$ body length; $\mathrm{HL}=$ head length; $\mathrm{PL}=$ pronotum length; $\mathrm{PW}=$ pronotum width (at posterior margin); TL = tegmen length; TW = tegmen (dorsal field) width; HWL $=$ hindwing length; HFL = hind femur length; HTL = hind tibia length.

Depositories. Specimens were deposited in:

FRC Forest Research Centre (Sepilok), Sabah Forestry Department, East Malaysia

UBDM Universiti Brunei Darussalam Museum, Brunei Darussalam

ZRC Zoological Reference Collection, Lee Kong Chian Natural History Museum, Singapore

\section{Taxonomy Part}

\section{Superfamily Grylloidea}

\section{Subfamily Phaloriinae}

Genus Borneloria Gorochov, 2018

Gorochov, 2018: 55

This recently erected genus consists of two species, both from Borneo (Cigliano et al., 2020): 
B. moorei (Chopard, 1940)

B. moorei moorei (Chopard, 1940)—Sarawak: Mount Dulit

B. moorei occidentalis Gorochov, 2018-Sarawak: Kubah

B. cuspis Gorochov, 2018-Sabah: Tawau Hills

This genus is characterised by male genitalia with large and undivided epiphallus and short ectoparameres, unpaired apodeme; presence of both inner and outer tympana; and head rostrum long and with the anteroventral edge more oblique in the profile (Gorochov, 2018).

\section{Borneloria cuspis Gorochov, 2018}

(Figs. 1-3)

Gorochov, 2018: 56

Material examined. 1 male (KB.19.1), Brunei Darussalam, Temburong District, Kuala Belalong Field Studies Centre, along Ashton Trail, N4.54736, E115.15707, 102.5 \pm 5.9 m.a.s.1., on foliage, 2005 hours, 11 July 2019, coll. M. K. Tan \& H. Yeo (UBDM).

Remarks. This species was described from Tawau Hills (Sabah). We now report the second locality known for this species, and the first record for Brunei Darussalam. Our specimen is clearly different from Borneloria moorei (Chopard, 1940), even though it can be found in Mount Dulit (not too far from Brunei).

\section{Subfamily Phalangopsinae}

\section{Genus Anemozara Gorochov, 2014}

Gorochov, 2014: 41

Four species from two subgenera are currently known from Borneo (Cigliano et al., 2020):

Subgenus Anemozara Gorochov, 2014

A. (A.) propria Gorochov, 2014-Sarawak: Lambir Hills

A. (A.) umbrosa Gorochov, 2014-Sarawak: Kubah

A. (A.) vera Gorochov, 2014-Sabah: Trus Madi

Subgenus Zacmozara Gorochov, 2014

A. (Z.) eximia Gorochov, 2014-Sarawak: Lambir Hills

All the male specimens from Brunei Darussalam belong to the subgenus Anemozara Gorochov, 2014 characterised by apical segment of maxillary palpi whitish and male genitalia with rather short and wide epiphallus having moderately narrow and bilobate apical lobule of posteromedian lobe directed upwards, with short and more or less simple ectoparameres, and with short rachis (as compared to subgenus Zacmozara Gorochov, 2014). We keep the two species from Brunei (with only male specimens) tentatively as putative species until we can confirm that they are distinct from the species from A. (A.) umbrosa and A. (A.) propria (both known only from females). These crickets are extremely well camouflaged in their natural environment (leaf litters) and are very active. This may explain why extremely little is known about this genus so far and very few materials have been collected.

\section{Anemozara sp. 1}

(Figs. 4A, 4B, 5A-C, 6A, 7A-D) 
Material examined. 1 male, (KB.19.32), Brunei Darussalam, Temburong District, Ulu Ulu Resort, along Belian Trail, N4.55660, E115.15462, 97.6 10.6 m.a.s.l., on leaf litter, 0850 hours, 16 July 2019, coll. M. K. Tan \& H. Yeo (UBDM).

Remarks. Our single male specimen from Temburong is distinctly different from the species from Belait, by the colouration and patterns (Figs. 4-6) and male genitalia (Fig. 7). It resembles A. (A.) vera Gorochov, 2014 from Trus Madi (but differs clearly by male genitalia) and A. (A.) umbrosa Gorochov, 2014 from Kubah in colour patterns, but we cannot verify if our male from Temburong is the same as A. (A.) umbrosa known only for females.

\section{Anemozara sp. 2}

(Figs. 4C-F, 5D-I, 6B, 6C, 7E, 7F)

Material examined. 1 male (BRU.19.24), Brunei Darussalam, Belait District, Andulau Forest Reserve, N4.62473, E114.51240, 64.5 \pm 8.0 m.a.s.l., on forest floor, 0940 hours, 26 February 2019, coll. M. K. Tan \& H. Yeo (UBDM); 1 male (BRU.19.66), Brunei Darussalam, Belait District, Jln Labi near Andulau Forest Reserve, N4.63355, E114.51044, 74.2 \pm 6.1 m.a.s.l., on leaf litter, 0850 hours, 7 July 2019, coll. M. K. Tan (ZRC).

Remarks. The species from Belait is clearly distinct from other congeners (with known males) by male genitalia. Its habitus resembles A. (A.) propria Gorochov 2014 from Lambir Hills (which is closer to Belait than from Belait to Temburong) but we only have male specimens whereas $A$. (A.) propria is known only for female.

\section{Genus Terrozacla Gorochov, 2014}

Gorochov, 2014: 63

Six species are known from Borneo and Sumatra (Cigliano et al., 2020):

T. borneo Gorochov, 2014-Borneo: Sabah: Trus Madi; Sarawak: Lambir Hills; Brunei Darussalam:

Belait (new locality record) and Kuala Belalong

T. gading Gorochov, 2014-Borneo: Sarawak: Gunung Gading

T. harau Gorochov, 2014-Sumatra: West Sumatra: Harau Valley

T. jambi Gorochov, 2014-Sumatra: Jambi: Mount Kerinci

T. kubah Gorochov, 2014-Borneo: Sarawak: Kubah

T. trusmadi Gorochov, 2014-Borneo: Sabah: Trus Madi

\section{Terrozacla borneo Gorochov, 2014}

(Fig. 9)

Gorochov, 2014: 68; Tan \& Wahab, 2018: 132

Material examined. 1 male (KB.19.5), Brunei Darussalam, Belait District, Teraja, along Jalan Labi,

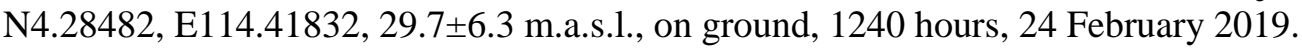

Remarks. This species was first described from Trus Madi (Sabah) and Lambir Hill (Sarawak).

Subsequently, Tan \& Wahab (2018) reported the occurrence of this species in Kuala Belalong (Brunei Darussalam). Unsurprisingly, we have now also found this species to occur in Belait (not far from Lambir Hills).

\section{Subfamily Itarinae}

Genus Itara Walker, 1869 
Ten subgenera are currently known (Cigliano et al., 2020), mostly differentiated by male genitalia: Bornitara Gorochov, 1997-nine species from Borneo

Gryllitara Chopard, 1931-five species from China, Malay Peninsula and Sumatra

Inditara Gorochov, 2009 — one species from India continent

Itara Walker, 1869-14 species from China, Indochina, Malay Peninsula, Borneo, Sumatra and Philippines

Maxitara Gorochov, 2001-five species from Borneo

Micritara Gorochov, 1997-two species from Borneo

Noctitara Gorochov, 1997-four species from Indochina

Phormincter Saussure, 1878-13 species from Borneo, Sumatra and Malay Peninsula

Singitara Gorochov, 1997- two species from Borneo and Malay Peninsula

Tinnitara Gorochov, 2007-two species from Borneo

\section{Subgenus Bornitara Gorochov, 1997}

Gorochov, 1997: 71; Ma \& Zhang, 2015: 530

Nine species are known (Cigliano et al., 2020):

I. (B.) borneoensis Gorochov, 1997-Sabah, Mount Kinabalu

I. (B.) chopardi Gorochov, 1997-Sarawak, Mount Murud

I. (B.) copiosa Gorochov, 2007-Sabah, Trus Madi

I. (B.) kalimantanensis Gorochov, 1997-Sabah, Gunung Mulu

I. (B.) latipennis Chopard, 1930-Sarawak, Mount Penrissen

I. (B.) matangi Gorochov, 2012-Sarawak, Kubah National Park

I. (B.) sabahensis Gorochov, 1997-Sabah, Sandakan

I. (B.) sarawakensis Gorochov, 1997-Sarawak, Gunung Mulu

I. (B.) trusmadi Gorochov, 2007-Sabah, Trus Madi

Itara (Bornitara) cuspis Tan \& Wahab, sp. nov.

(Figs. 9-11)

Material examined. Male holotype (KB.19.9), Temburong District, Kuala Belalong Field Studies Centre, attracted to light, 12 July 2019, coll. M. K. Tan \& H. Yeo (UBDM).

Diagnosis. This new species differs from congeners by epiphallus fairly broad, with a distinct dorsal spine (ds) at middle of epiphallus, with large ventral spine (vs) and fairly long and slightly hooked apex (ap), ectoparameres (ec) with distinctly shaped anterior half and long and cylindrical posterior half; and tegminal venation with well-developed additional vein connecting all oblique veins near $\mathrm{CuA}$.

Comparison with congeners. The new species resembles $I$. (B.) latipennis Chopard, 1930 and $I$. (B.) matangi Gorochov, 2012 most, both from the southern part of Sarawak relatively far from Brunei Darussalam, by shape of male genitalia and tegminal venation; but differs from $I$. (B.) latipennis by ventral spine (vs) on epiphallus longer in profile (more similar to $I$. (B.) matangi), apex of epiphallus more strongly hooked (ap) in profile (similar to $I$. (B.) matangi) and anterior emargination (ae) narrower; from $I$. (B.) matangi by posterior half of epiphallus not so strongly concave and narrow in dorsal view; differs from both $I$. (B.) latipennis and $I$. (B.) matangi by epiphallus with distinct dorsal spine (ds) at middle of epiphallus and ectoparameres (ec) posterior process slenderer and more elongated, touching each other at apex in ventral view. This new species also differs from $I$.

(B.) chopardi Gorochov, 1997 from Murud (not too far from Brunei) by presence of well-developed additional vein connecting all oblique veins near $\mathrm{CuA}$ (instead of interrupted near the longest oblique vein).

Description. Habitus very typical of the genus, relatively large and somewhat dorsoventrally compressed (Fig. 9A). Head rounded, very finely pubescent; rostrum 1.7 times as wide as scapus, with apex truncated (in dorsal view) (Fig. 9B); scapus stout; maxillary palpi slender and elongated, 
with apical segment longest, obliquely clavate and apex truncated (Fig. 9C); eyes oval in dorsal view (Fig. 9B), oblong in lateral view (Fig. 9C); median ocellus round and small; lateral ocelli oblong and large, located near eyes (Fig. 9D). Pronotal disc 1.8 times as wide as long, distinctly widening posteriorly (anterior margin 0.6 times as wide as posterior margin); finely pubescent with strong hairs along anterior and posterior margins; anterior margin of disc straight to slightly concave (when dried); posterior margin of disc slightly convex (Fig. 9B). Pronotal lateral lobe 1.6 times as long as high, with ventral margin straight (Fig. 9C). Fore and middle legs generally pubescent (especially along ventral margin), with a few stout setae usually located along dorsal margin; tarsus with a row of stout setae on ventral surface. Fore tibia with distinctly swollen on inner side, with inner tympanum very elongated slit-like, with outer tympanum open and having large, elongate, oblong tympanal membrane. Hind femur finely pubescent, without ventral spines; hind tibia also pubescent, with about 8 small and stout denticules at anterior half on each dorsal side, with 5 long dorsal subapical spurs on inner and outer margins; hind basitarsus with about 6 inner and 6 outer denticles.

Metanotal gland (Fig. 9E) with roundly curved transverse concavity in anterior part of metanotum, large and low median convexity on middle part, rather large and shallow concavity (approximately coincident with much lighter area at centre of metanotum) at apex of this concavity, and an oval whitish tubercle and keel-like structures behind this concavity.

Tegmen (Fig. 10) very finely pubescent, extending beyond abdominal apex, with dorsal field longer than lateral field; with four oblique veins in harp area, and well developed additional vein connecting all oblique veins near $\mathrm{CuA}$; tegminal mirror large, 1.5 times as wide as long, with anterior margin angular, with posterior margin widely rounded, with a sinuous dividing; anal area of tegmen longer than length of mirror; lateral field wide, with 10 parallel strong branches of Sc and about 7 cross-veins (often indistinct) between R and M (Fig. 10); R and M mostly parallel, strongly diverging towards apex; hind wings slightly surpassing tegmina (Fig. 10).

Anal plate tongue-shaped, with lateral keel distinct in anterior half (Fig. 11A). Subgenital plate elongated, gradually narrowing to subacute apex (Fig. 11A).

Male genitalia as shown in Figs. 11B-D: Epiphallus in dorsal view elongated but fairly broad, gradually narrowing to apex, lateral margin slightly concave after middle, apex somewhat truncated; in ventral view with plate-like structure in apical half, this plate with anterior margin faintly sinuous and narrowly emarginated in middle, laterally produced into ventrad-pointing spine (vs); in profile with characteristics S-shaped dorsal edge, with a distinct dorsal spine at middle of epiphallus (ds), lacks row of denticles on ventral surface, apex strongly curved upwards and faintly hooked (ap), ventral margin with a relatively large spine in middle, anterior emargination (ae) narrow. Ectoparameres (ec) with anterior half wide, inner lobe rounded; posterior half cylindrical, elongated (as long as length of anterior half), slightly curved with apex obtuse.

Female. Unknown.

Colouration. Body generally brown (Fig. 9A). Head and pronotum dark brown (Fig. 9B); scapus and pedicel slightly lighter in colouration; frons yellow brown; gena whitish immediately ventral of eye and then dark brown; maxillary palpi greyish. Tegminal dorsal field mostly transparent with tint of grey, veins usually darker (but not always), anal area infumated yellow brown; area between M, R and Sc infumated dark brown; lateral tegminal field pale mostly transparent with darker brown veins (Fig. 10). Hind wings infumated dark. Legs generally with coxae pale, femora pale brown except near knees which are darker, tibiae and tarsi brown. Abdominal tergites grey brown, sternites yellow brown.

Measurements (in mm). Male holotype $\mathrm{BL}=15.9 ; \mathrm{HL}=1.9 ; \mathrm{PL}=2.4 ; \mathrm{PW}=4.3 ; \mathrm{TL}=14.8$; $\mathrm{TW}=6.4 ; \mathrm{HWL}=4.1 ; \mathrm{HFL}=7.0 ; \mathrm{HTL}=5.8$.

Etymology. The species name refers to the characteristic distinct dorsal spine (ds) at middle of epiphallus (cuspis $=$ point or spike, feminine).

\section{Subfamily Podoscirtinae}

Aphonoides Chopard, 1940 
Chopard, 1940: 201; Otte \& Alexander, 1983: 344; Gorochov, 1986: 521; Desutter-Grandcolas, 1990: 234; Yin \& Zhang, 2001: 87; Gorochov, 2007: 237; Gorochov, 2008: 22; Desutter-Grandcolas et al., 2016: 442

Currently, 74 species are known. Most species were described from Asia and Australia, with a few species from tropical Africa and South America. Five species were described from Borneo (Cigliano et al., 2020):

A. hollowayi Gorochov, 2007-Borneo: Sarawak: Gunung Mulu

A. karnyi Chopard, 1940-Borneo: Sarawak: Mount Dulit (lectotype locality), Gunung Mulu

A. sabahi Gorochov, 2007-Borneo: Sabah: Tawai Plateau

A. sarawaki Gorochov, 2007- Borneo: Sarawak: Gunung Mulu

A. tawai Gorochov, 2007- Borneo: Sabah: Tawai Plateau

\section{Aphonoides duri Tan \& Wahab, sp. nov.}

(Figs. 12-14)

Material examined. Male holotype (BRU.19.77), Brunei Darussalam, Belait District, Andulau Forest Reserve, N4.62158, E1114.51324, 66.6 \pm 6.0 m.a.s.l., on foliage, 1928 hours, 9 July 2019, coll. M. K. Tan (UBDM).

Diagnosis. This new species differs from congeners by the combination of these characters: Dorsum of head brown with margins of rostrum pale and a transverse white band in middle; frons pale with black transverse stripes bordering inner and ventral margin of antennal scrobe and reaching eye; pronotal dorsal disc mostly dark brown, margins pale brown; with pairs of pale spots; pronotal lateral lobe pale yellow, with irregular dark patch and small dark spots; tegmen unicolourous yellow brown with veins darker brown; male genitalia with apical epiphallic process triangular and pointing with apex acute external margin angularly convex in middle (in dorsal view) and rounded at apex (in lateral view), with ectoparameres with dorsal lobe distinctly longer and larger than ventral lobe.

Comparison with congeners. This new species is most similar to A. sarawaki Gorochov, 2007 from Gunung Mulu (not very far from Belait) in male genitalia and colour patterns but differs distinctly by pale face with a dark stripe (instead of nearly completely black above mouthparts). Male genitalia differs by apical epiphallic process with more acute apex in dorsal view and rounded at apex (in lateral view); ectoparameres with dorsal lobe distinctly longer and larger than ventral lobe.

This species also differs from Bornean congeneric A. ?cinereus (Haan, 1844) (sensu Gorochov, 2007) by apical epiphallic process not dorso-ventrally flattened (in profile) and not truncated at apex and pattern on head and frons; from A. hollowayi and A. karnyi by body with numerous dark spots (instead of unicolourous light brown), male genitalia most roundish and stout and vastly different shape of apical epiphallic process; from A. sabahi by shape of apical epiphallic process not truncated in dorsal view and without small apical spinule, and head dorsum and pronotal disc brown (instead of light grey with sparse dark spots) and pronotal lateral lobe with more dark patterns; from A. tawai by shape of apical epiphallic process not long and spine-like.

Colour patterns of head and frons is very similar to A. gialai Gorochov, 2007 from Vietnam (known only from female) but differs by pronotum with more dark patterns and spots.

Description. Habitus typical of genus (Fig. 12). Head rostrum triangular, 1.7 times as wide as scapus, 1.2 times as wide as eye, with apex truncated (in dorsal view) (Fig. 12A). Scapus elongated (Fig. 12C). Eyes distinctly vertically oblong, projected anteriorly (Fig. 12A); median ocellus transverse, distinctly wider than long and located between scapi; lateral ocellus between postero-inner margin of scapus and anterior margin of eye, rounded. Maxillary palpi somewhat stout, cylindrical, with apical (fifth) and subapical segments swollen distally; apical segment with apex obtuse; apical, subapical and third segments subequal length (Fig. 12B). Pronotal disc 0.9 times as long as wide, anterior margin straight, posterior margin strongly angular in middle, widen posteriorly (posterior margin 1.5 times as wide as anterior margin) (Fig. 12A). Pronotal lateral lobe 1.2 times as long as high, finely pubescent and margin with longer and thicker setae (especially the posterior margin) (Fig. 12C). Fore tibia with large elongated oval and open inner tympanum and without outer tympanum; 
fore and middle legs generally finely pubescent, with a few stout setae located along ventral margin; without subapical spines on ventral margins.

Male. Tegmen extending beyond abdominal apex and knee of hind femur; dorsal field longer than lateral field; dorsal field with four main longitudinal veins with numerous cross veins; basal most vein splits at base on anal side (Fig. 11B). Lateral field with numerous very faint cross veins between $\mathrm{M}$ and Sc (Fig. 11C); Sc with 5 branches with a few cross-veins between branches (Fig. 11C). Hind wings surpassing tegmina.

Male genitalia stout and rounded as shown in Fig. 14: epiphallus transverse, with posterior margin broadly emarginated and somewhat truncated in middle of emargination. Apical epiphallic process in dorsal and ventral view triangular and pointing with apex acute, external margin with angular convex in middle; in lateral view with apex rounded, dorsal and ventral margin at distal half faintly converging towards apex. Ectoparameres with two apical lobes; dorsal lobe larger and elongated, with apex rounded; ventral lobe distinctly shorter with apex distinctly more acute (in lateral view).

Female. Unknown.

Colouration. Head, pronotum and legs generally pale yellow with numerous dark patterns and spots (Fig. 11). Dorsum of head brown with black spot beside lateral ocellus; margins of rostrum pale, a transverse white band in middle (Fig. 12A). Frons pale with black stripes bordering inner and ventral margin of antennal scrobe and reaching eye (Fig. 12C). Scapus pale yellow with brown patches. Maxillary palps generally pale with tint of dark (Fig. 12C). Pronotal dorsal disc mostly dark brown, margins pale brown; with pairs of pale spots, small pyriform spot just behind anterior margin, a larger pyriform spot with a black spot inside in middle, and smaller oval spot after middle (Fig. 12A). Lateral lobe pale yellow, with irregular dark patch and small dark spots (Fig. 12C). Fore and middle femora mostly pale brown some irregular dark patch towards distal end; fore and middle tibiae somewhat banded. Hind femur pale brown, with dorsal dark brown spot in middle and band near knee, external surface mostly with numerous brown stripes. Hind tibia pale brown with two broad dark band, one after knee and the other slightly after middle. Tegmen unicolourous yellow brown with veins darker brown (Fig. 11). Abdominal tergite dark brown with distal margin yellow sternite pale and dark grey in middle (Fig. 12D).

Measurements (in mm). Male holotype $\mathrm{BL}=9.4 ; \mathrm{HL}=1.1 ; \mathrm{PL}=2.3 ; \mathrm{PW}=2.6 ; \mathrm{TL}=11.6 ; \mathrm{TW}$ $=1.5 ; \mathrm{HWL}=2.8 ; \mathrm{HFL}=6.1 ; \mathrm{HTL}=7.9$.

Etymology. The species name refers to the characteristics thorn-like epiphallic apical process (in dorsal view) and acute ventral lobe of ectoparamere (in lateral view) (duri = thorn in Bahasa Malay), noun in apposition.

\section{Genus Varitrella Gorochov, 2003}

Two subgenera consisting of 20 species from Southeast Asia are currently known (Cigliano et al., 2020).

\section{Subgenus Cantotrella Gorochov, 2006}

Gorochov, 2006: 33; Gorochov \& Tan, 2014: 536

The subgenus Cantotrella differs from Varitrella by the absence of metanotal gland in male, apical part of rachis (= guiding rod) in male genitalia widened and with comparatively small lobes (including a virga-like or finger-like median process), and ectoparameres (when developed) probably originated from lateral lobes of epiphallus but not from lateral lobes of rachis (Gorochov \& Tan, 2014). 18 species are currently known (Cigliano et al., 2020):

C. (V.) amoena Gorochov, 2014-Borneo: Sabah: Trus Madi

C. (V.) bakeri (Chopard, 1925)—Philippines: Mindanao: Surigao

C. (V.) conspersa (Stål, 1877)_Philippines

C. (V.) depressa Gorochov, 2003-Philippines 
C. (V.) glabra (Ingrisch, 1997) - Indochina: Thailand: Surat Thani

C. (V.) manukan Gorochov, 2014-Borneo: Sabah: Manukan Island

C. (V.) mindoroensis Gorochov, 2006-Philippines: Mindoro

C. (V.) mjobergi (Chopard, 1930)—Borneo: Sarawak: Mt. Dulit

C. (V.) orion Tan \& Gorochov, 2014-Malay Peninsula: Singapore

C. (V.) palawanensis Gorochov, 2006-Philippines: Palawan

C. (V.) quadrata (Haan, 1844) - Java, Borneo

C. (V.) robusta Gorochov, 2014-Sulawesi: Bunaken Island

C. (V.) saussurei (Stål, 1877) -Philippines

C. (V.) striata Gorochov, 2014-Borneo: Sarawak: Mount Matang

C. (V.) sukau Gorochov, 2014-Borneo: Sabah: Sandakan

C. (V.) tawau Gorochov, 2014-Borneo: Sabah: Tawau Hills

C. (V.) trusmadi Gorochov, 2014-Borneo: Sabah: Trus Madi

C. (V.) variabilis Gorochov, 2006-Philippines: Palawan

\section{Varitrella (Cantotrella) suikei Tan, Japir \& Chung, sp. nov.}

(Figs. 15-18)

Material examined. Male holotype (SDK.19.78), East Malaysia, Sabah, Sandakan, Kabili Sepilok Forest Reserve, N5.86985, E117.93805 6, 9.8 7.7 m.a.s.l., on foliage, 1 October 2019, coll. M. K. Tan, R. Japir \& J. Lee Yukang (FRC).

Diagnosis. This new species differs from congeners by male genitalia with dorso-anterior epiphallic spine more laterally pointed; ectoparameres stout and strongly curved with apex acute; and rachis surpassing lateral lobe of epiphallus and with apex strongly emarginated.

Comparison with congeners. This new species resembles Bornean congeners but differs by dorso-anterior epiphallic spine (ds) more laterally pointed than V. mjobergi, V. striata and V. trusmadi, appearing shorter in profile (instead of absent in $V$. quadrata); ectoparameres (ec) stouter and more strongly curved in profile than $V$. striata and $V$. trusmadi; rachis (ra) more strongly emarginated at apex than $V$. striata (instead of truncated to faintly emarginated in $V$. amoena, $V$. sukau, V. tawau, and $V$. trusmadi). It also differs from $V$. manukan by presence of dorsal epiphallic spine (ds), lateral apical lobe of epiphallus (al) not pointing dorsad at apex, ectoparameres (ec) curved and pointing ventrad posteriorly (instead of dorsally) and rachis (ra) with apical emargination wider. The new species also differs from V. sukau from Sandakan by distinctly shorter dorsal epiphallic spine (ds) and shape of ectoparameres.

Description. Habitus very typical of the genus, medium sized (Fig. 15). Head with dorsum slightly flattened, very finely pubescent; rostrum 1.1 times as wide as scapus, with apex truncated (in dorsal view) (Fig. 16A); scapus large and elongated; maxillary palpi with apical segment longest, cylindrical and oblong with obtuse apex, with subapical segment shorter than third segment (Fig. 16B); eyes projected anteriorly in dorsal view (Fig. 16A); median ocellus round and small; lateral ocelli oblong and large, located near eyes. Pronotal disc 1.4 times as wide as long, faintly widening posteriorly (posterior margin 1.2 times as wide as anterior margin); finely and densely pubescent; anterior margin of disc distinctly concave in middle; posterior margin of disc nearly straight to slightly convex (Fig. 16A). Pronotal lateral lobe 1.4 times as long as high, with ventral margin straight (Fig. 16B). Metanotal gland absent (Fig. 16C). Fore tibia slightly swollen, with inner tympanum slit-like, with outer tympanum open and having elongate, oval tympanal membrane; hind tibiae with 7 inner and 5 outer long spines in distal half, 2-6 denticles spines, with small denticles before most proximal spines, and with inner spurs (apical spines) longer than corresponding outer ones.

Tegmen (Fig. 16D) covering abdomen and surpassing apex of hind femur; with mirror 1.5 times as long as wide, dividing vein typical of subgenus; with 5 veins in harp area; with around 16 branches on Sc (Fig. 16D); hind wings clearly surpassing tegmina.

Anal plate broad, with two whitish oval parts at base, slightly indented at apex (Fig. 16E). Subgenital plate typical of subgenus.

Male genitalia as shown in Fig. 17: Epiphallus in dorsal view with dorso-anterior epiphallic spine (ds) strongly sclerotised, somewhat laterally pointed, lateral margin concave, posterior end produced 
into two latero-apical lobular parts (al), deeply V-emarginated between latero-apical lobules; in profile with posterior part rounded with a dorso-apical spinule and two smaller spinules on dorsal margin, dorsal margin straight. Ectoparameres (ec) hooked-like, curved tapering into an acute apex, and pointing ventrad posteriorly. Rachis (ra, guiding rod) rather long, but not surpassing epiphallus, produced into two lateral lobes (lo) at posterior end, with apical emargination wider between lateral lobes in dorsal view; lateral lobe (lo) strongly widened and roundly rectangular in profile.

Endoparameral apodemes (ae) very long, narrowing and converging towards each other anteriorly. Female. Unknown.

Colouration. Body generally grey-brown (Fig. 15). Head and pronotum with few dark spots (more in pronotal lateral lobe), but not as plentiful as some congeners (Figs. 16A, 16B); scapus and pedicel slightly lighter in colouration; maxillary palps with apical segment dark distally. Tegminal dorsal field yellowish, with some darker infumation but not obvious, veins range from yellow to dark; with a dark patch where the stridulatory file, diagonal and chords converge and a dark strip between mirror and $\mathrm{CuA}$ (Fig. 16D). Lateral tegminal field paler, almost transparent with darker brown veins, with small black spots near Sc between branches of Sc (Fig. 16E). Hind wings transparent. Legs generally pale brown with irregular and sparse dark spots. Thoracic and abdominal segments yellow brown to brown; anal plate brown with two whitish oval parts at base and another whitish spot before apex.

Measurements (in mm). Male holotype $\mathrm{BL}=16.9 ; \mathrm{HL}=2.8 ; \mathrm{PL}=2.7 ; \mathrm{PW}=4.0 ; \mathrm{TL}=18.7$; $\mathrm{TW}=4.0 ; \mathrm{HFL}=14.0 ; \mathrm{HTL}=13.1$.

Etymology. This new species is named after Sui-Kei (first name) Lee (last name), noun in apposition.

Calling song (Fig. 18). The song consists of doublets of syllables at length to form a continuous trill. Each syllable has a duration of $25.1 \pm 2.0 \mathrm{~ms}(21.9-28.1 \mathrm{~ms})$; each doublet has a duration of $69.4 \pm 2.2 \mathrm{~ms}(67.2-73.4 \mathrm{~ms})$ and period of $320.4 \pm 62.4 \mathrm{~ms}(246.9-417.2 \mathrm{~ms})$. The spectrum shows a dominant peak at $6.44 \pm 0.03 \mathrm{kHz}$ (also the fundamental frequency), followed by the second dominant peak at $12.85 \pm 0.13 \mathrm{kHz}$ and several peaks harmonically related.

\section{Acknowledgements}

The authors are thankful to Huiqing Yeo (in Brunei Darussalam), Momin Binti, John Lee Yukang and Saudi Bintang (in Sandakan) for field assistance. The permissions for collecting and exporting material were granted by the Forestry Department, Ministry of Primary Resources and Tourism, Brunei Darussalam (JPH/PDK/01 Pt 2 and BioRIC/HOB/TAD/51-80 respectively) and the Sabah Biodiversity Centre (JKM/MBS.1000-2/3 JLD.3 (99)) (for Sandakan). The work of MKT was supported by the Orthoptera Species File Grant 2019 under the taxonomic research project titled "Contribution to the species diversity and acoustic data on Orthoptera from Sandakan (Borneo, East Malaysia, Sabah)"; and Percy Sladen Memorial Fund (The Linnean Society of London) under the project titled "Advancing biodiversity informatics of Orthoptera from Brunei Darussalam". The bioacoustics component was supported by the Wildlife Acoustics Scientific Product Grant 2019 under the project titled "Discovery of Ultrasonic Singing Katydids in Southeast Asia".

\section{References}

Baroga-Barbecho, J. B., Tan, M. K., Yap, S. A. \& Robillard, T. (2020, unpublished). Taxonomic study of Lebinthus Stål, 1877 (Orthoptera: Gryllidae: Eneopterinae) with description of six new species in the Philippines. Zootaxa

Cigliano, M.M., Braun, H., Eades, D.C. \& Otte, D. (2020) Orthoptera Species File online. Version 5 (5.0). Available from: http://orthoptera.speciesfile.org/HomePage/Orthoptera/HomePage.aspx (accessed 26 May 2020)

Chopard, L. (1940) Results of the Oxford University expedition to Sarawak (Borneo), 1932. Gryllacridae and Gryllidae (Orthoptera). The Entomologist's Monthly Magazine, 476 (8-9), 189204.

Desutter-Grandcolas, L. (1990) Étude phylogénétique, biogéographique et écologique des Grylloidea néotropicaux (Insectes, Orthoptères). 347 pp. 
Desutter-Grandcolas, L. Anso, J. \& Jourdan, H. (2016) Crickets of New Caledonia (Insecta, Orthoptera, Grylloidea): a key to genera, with diagnoses of extant genera and descriptions of new taxa. Zoosystema, 38 (4), 405-452. https://doi.org/10.5252/z2017n1a15

Gorochov, A.V. (1986) System and morphological evolution of crickets from the family Gryllidae (Orthoptera) with description of new taxa. Communication 1. Zoologicheskii Zhurnal, 65 (4), 516 527.

Gorochov, A.V. (1997) Partial revision of the subfamily Itarinae (Orthoptera: Gryllidae). Zoosystematica Rossica, 6 (1-2), 47-75.

Gorochov, A.V. (2006) Taxonomy of Podoscirtinae (Orthoptera: Gryllidae). Part 5: New IndoMalayan and Madagascan Podoscirtini. Zoosystematica Rossica, 15 (1), 33-46.

Gorochov, A.V. (2007[2006]) Taxonomy of Podoscirtinae (Orthoptera: Gryllidae). Part 6: IndoMalayan Aphonoidini. Zoosystematica Rossica, 15 (2), 237-289.

Gorochov, A.V. (2008) Taxonomy of Podoscirtinae (Orthoptera: Gryllidae). Part 7: AustraloOceanian Aphonoidini and geography of the tribe. Zoosystematica Rossica, 17 (1), 15-50.

Gorochov, A.V. (2014) Classification of the Phalangopsinae subfamily group, and new taxa from the subfamilies Phalangopsinae and Phaloriinae. Zoosystematica Rossica, 23 (1), 7-88.

Gorochov, A.V. (2015) Evolution and taxonomic significance of the copulatory apparatus in Ensifera (Orthoptera). Part 2: Male genitalia in Grylloidea (Orthoptera: Ensifera). Zoosystematica Rossica, 24 (1), 31-41.

Gorochov, A.V. (2018) Taxonomic studies on the cricket subfamilies Pteroplistinae, Phaloriinae and Cacoplistinae (Orthoptera: Gryllidae) from the Old World. Zoosystematica Rossica, 27 (1), 40-76.

Gorochov, A. V. \& Tan, M. K. (2014) Species of the subgenus Cantotrella (Orthoptera: Gryllidae: Podoscirtinae: Varitrella) from Singapore, Malaysia and Indonesia. Zootaxa, 3774 (6), 535-551. http://dx.doi.org/10.11646/zootaxa.3774.6.3

Ma, L. \& Zhang, Y. (2015) Revision of the cricket species of the subfamily Itarinae (Orthoptera: Gryllidae) from China. Canadian Entomologist, 147 (5), 527-540. https://doi.org/10.4039/tce.2014.68

Otte, D. \& Alexander, R.D. (1983) The Australian crickets (Orthoptera: Gryllidae). Monographs of the Academy of Natural Sciences of Philadelphia, 22, 1-477.

Ragge, D.R. \& Reynolds, W.J. (1998) The songs of the grasshoppers and crickets of Western Europe. Colchester, England: Harley Books, 612 pp.

R Core Team (2018) R: A language and environment for statistical computing. R Foundation for Statistical Computing, Viennan. [program]

Sueur, J., Aubin, T. \& Simonis, C. (2008) Seewave, a free modular tool for sound analysis and synthesis. Bioacoustics, 18 (2), 213-226. https://doi.org/10.1080/09524622.2008.9753600

Tan, M.K., Japir, R., Chung, A.Y.C. \& Robillard, T. (2019a) Crickets of the subfamily Eneopterinae (Orthoptera: Grylloidea) from Sandakan, Sabah: one new species and calling songs of a sympatric species. Zootaxa, 4619 (2), 347-363. https://doi.org/10.11646/zootaxa.4619.2.9

Tan, M.K., Gorochov, A.V., Japir, R., Chung, A.Y.C. \& Wahab, R.A. (2019b) New taxa of crickets (Orthoptera: Grylloidea: Gryllinae, Phaloriinae and Pteroplistinae) from northern Borneo (Belait and Sandakan). Zootaxa, 4661 (1), 101-117. https://doi.org/10.11646/zootaxa.4661.1.4

Tan, M.K. \& Wahab, R.A. (2018) Preliminary study on the diversity of Orthoptera from Kuala Belalong Field Studies Centre, Brunei Darussalam, Borneo. Journal of Orthoptera Research, 27 (2), 119-142. https://doi.org/10.3897/jor.27.24152

Yin, H. \& Zhang, W. (2001) A new species of Aphonoides Chopard (Orthoptera: Grylloidea: Eneopteridae) from China. Entomotaxonomia, 23 (2), 87-89.

\section{Figure captions}



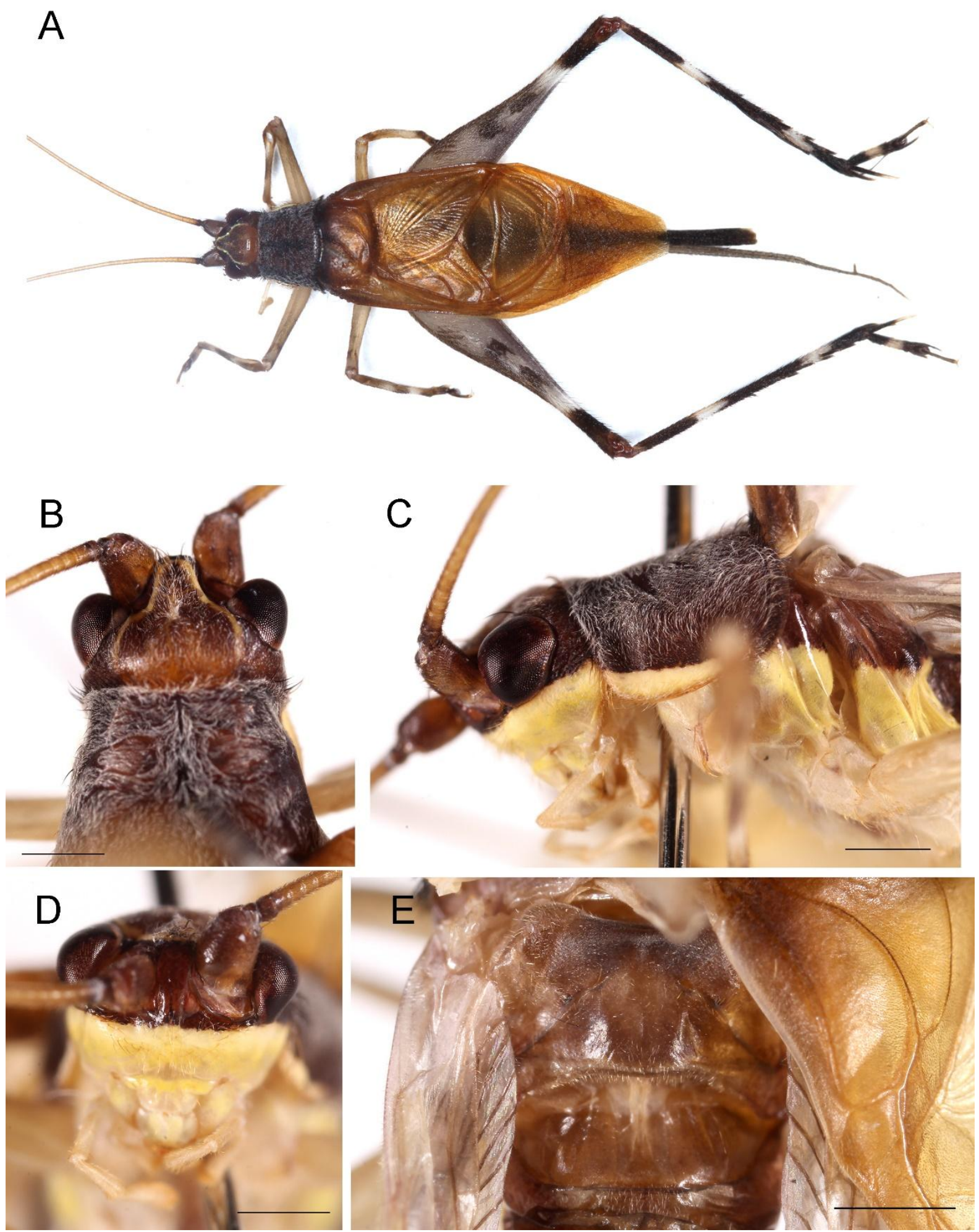

FIGURE 1. Borneloria cuspis Gorochov, 2018 male habitus in dorsal view (A), head and pronotum in dorsal (B) and lateral (C) views; face in anterior view (D), metanotal area in dorsal view (E). Scale bars: $1 \mathrm{~mm}$. 


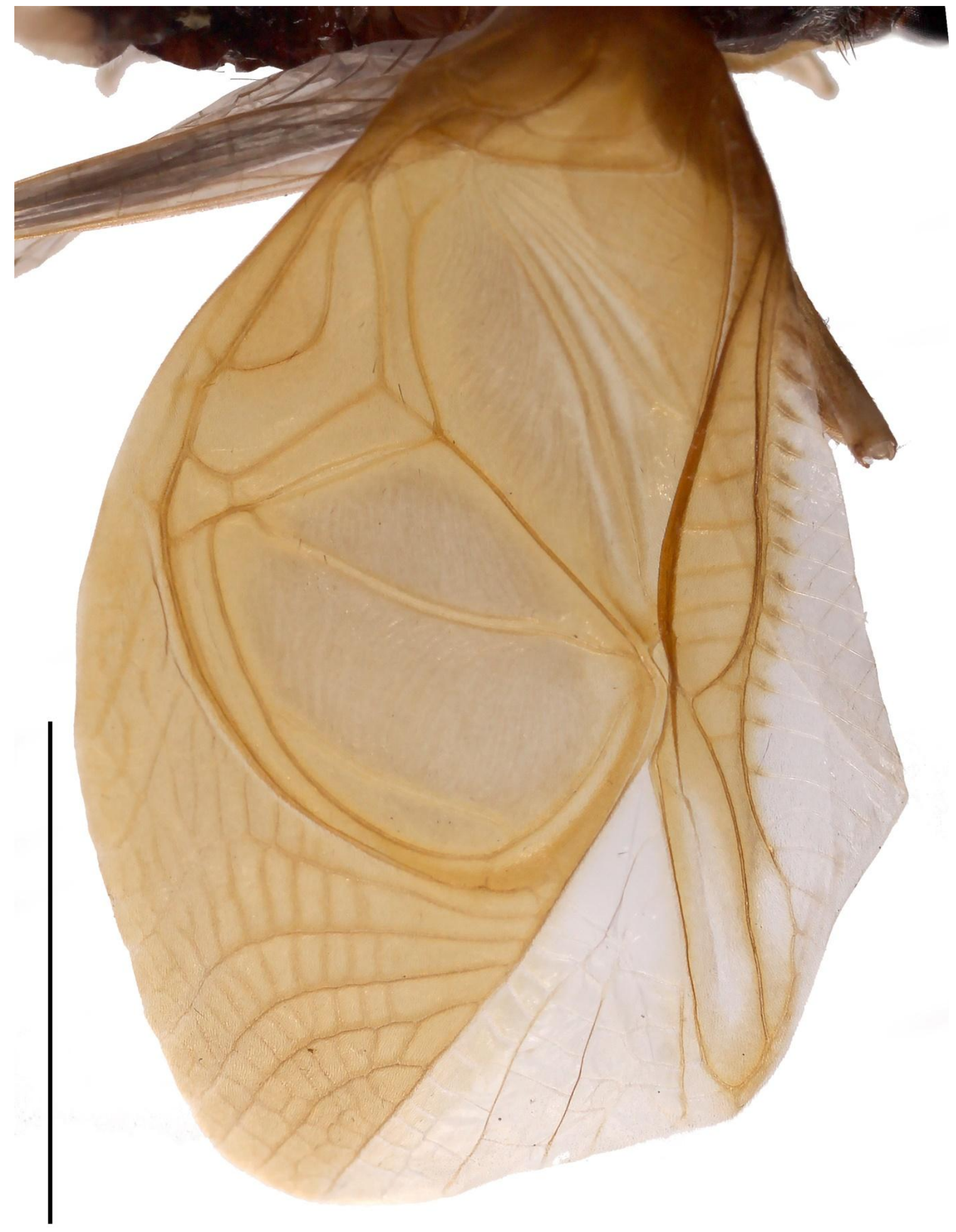

FIGURE 2. Borneloria cuspis Gorochov, 2018 male tegmen in dorsal view. Scale bar: $5 \mathrm{~mm}$. 


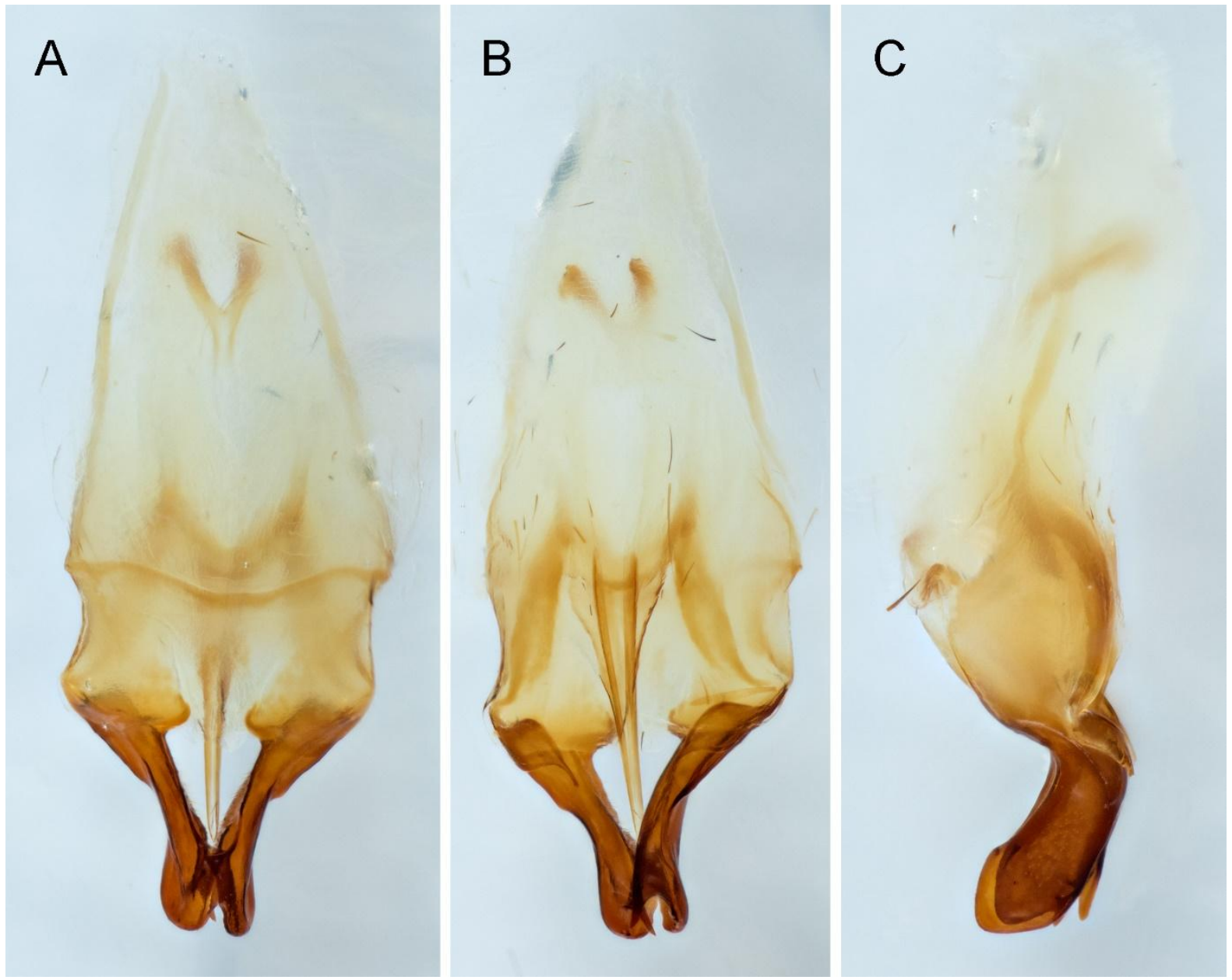

FIGURE 3. Borneloria cuspis Gorochov, 2018 male genitalia in dorsal (A), ventral (B) and lateral (C) views. 

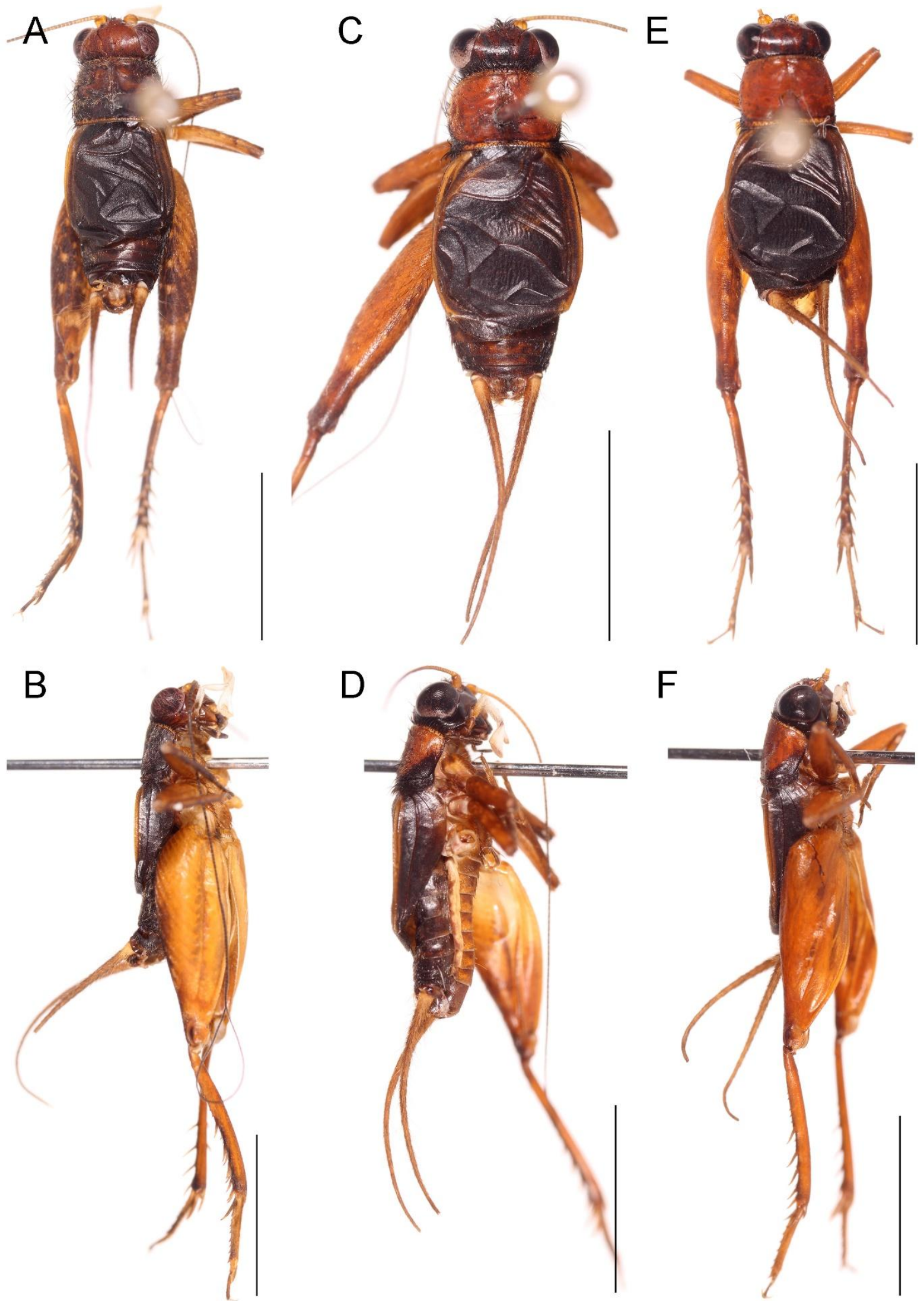

FIGURE 4. Anemozara species 1 (A, B) and $2(\mathrm{C}-\mathrm{F})$ males in dorsal (A, C, E) and lateral (B, D, F) views. Scale bars: $5 \mathrm{~mm}$. 

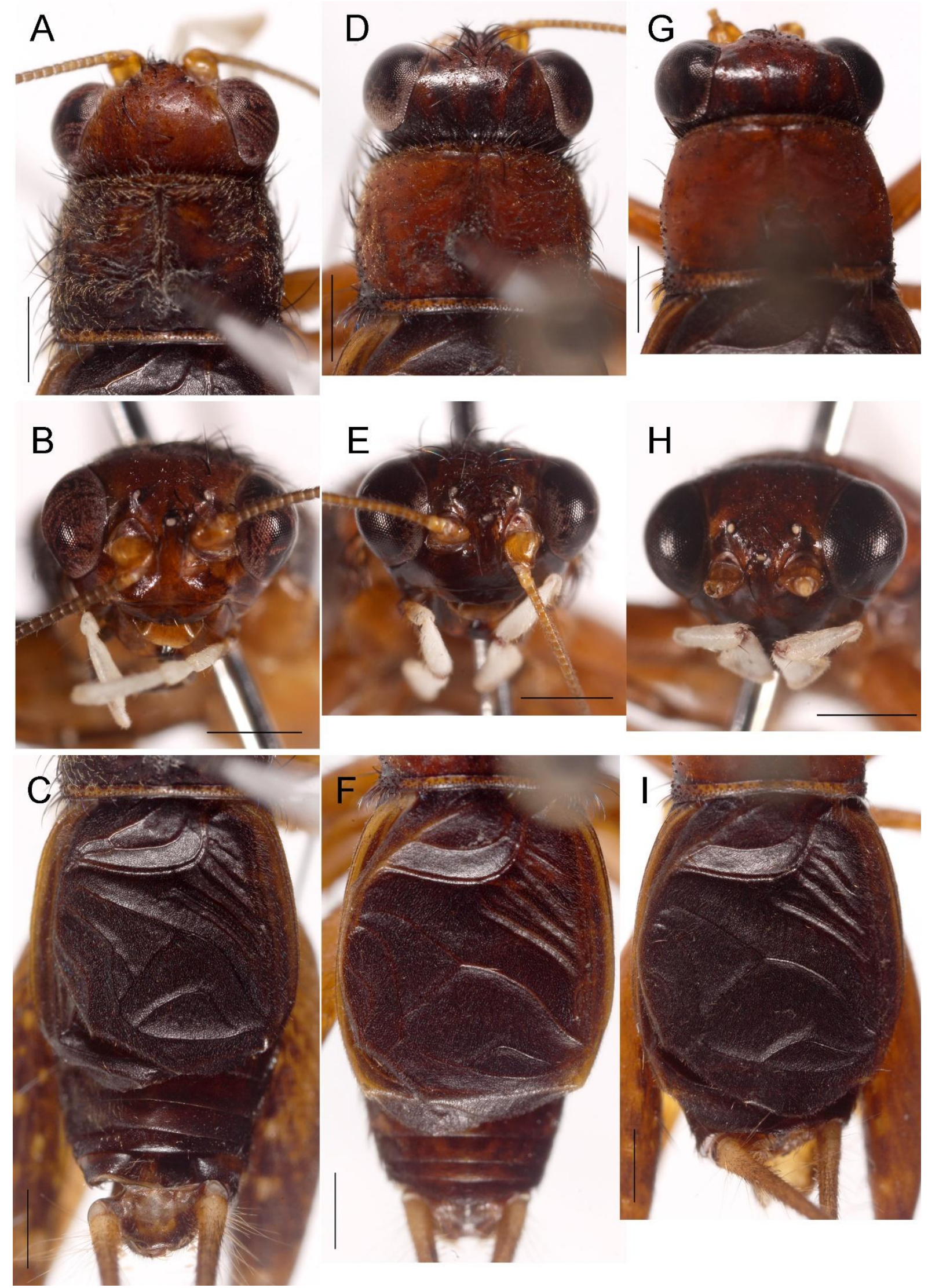

FIGURE 5. Anemozara species 1 (A-C) and 2 (D-I) males: head and pronotum in dorsal view (A, D, $\mathrm{G})$, face in anterior view (B, E, H) and tegmen and abdomen in dorsal view (C, F, I). Scale bars: 1 $\mathrm{mm}$. 

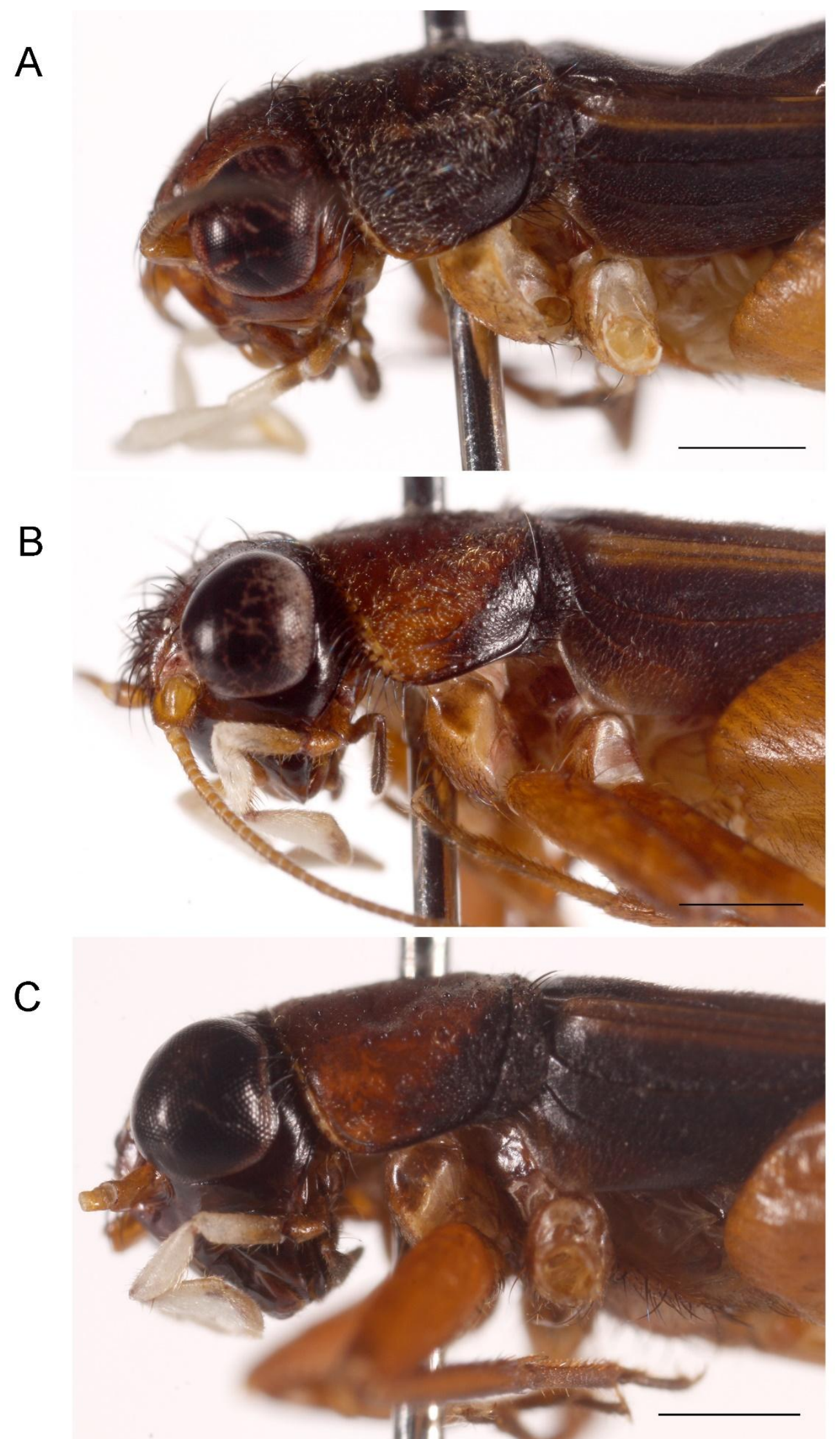

FIGURE 6. Anemozara species 1 (A) and 2 (B, C) males head and pronotum in lateral view. Scale bars: $1 \mathrm{~mm}$. 
A
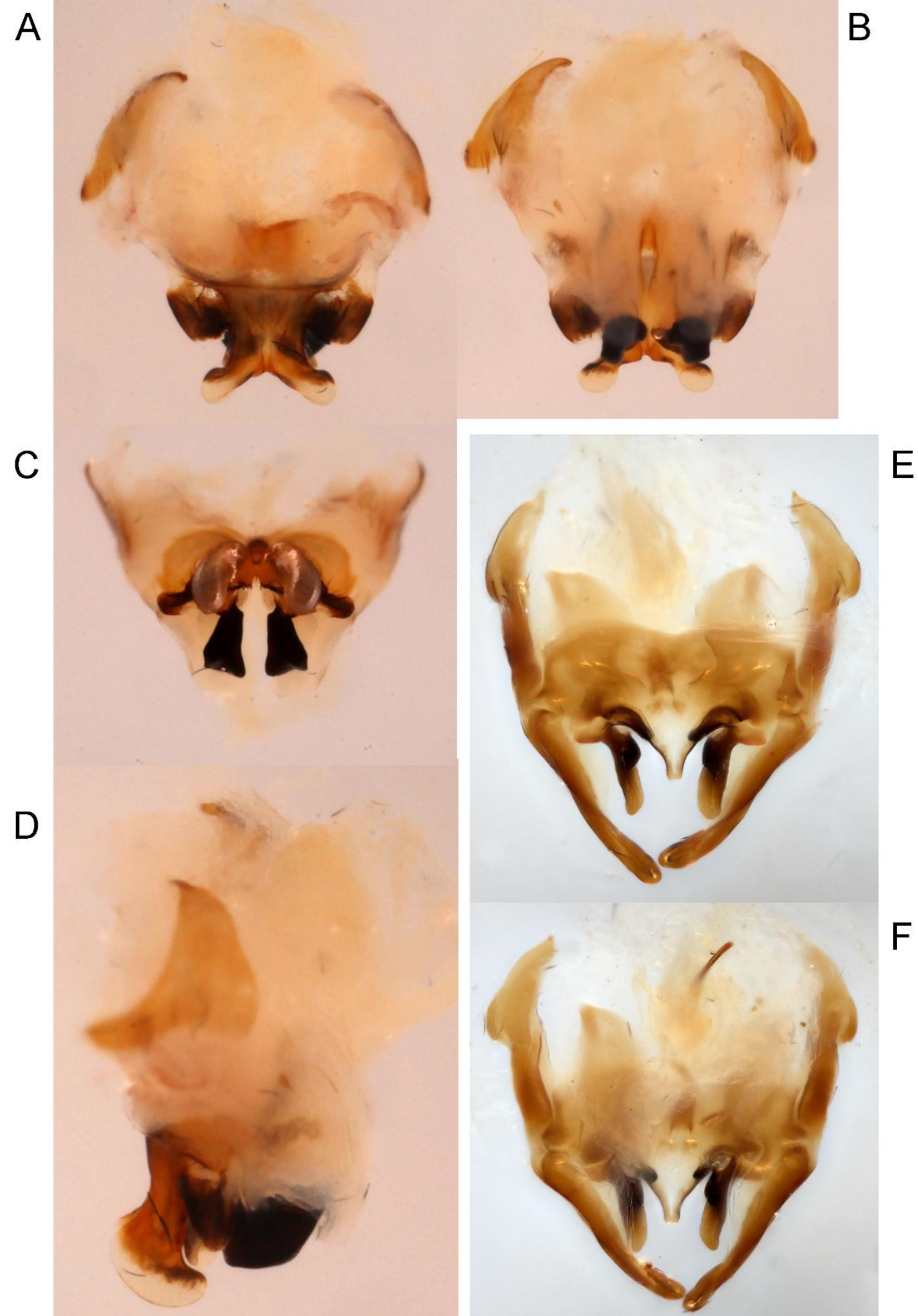

FIGURE 7. Anemozara species $1(\mathrm{~A}-\mathrm{D})$ and $2(\mathrm{E}, \mathrm{F})$ male genitalia in dorsal (A, E), ventral (B, F), anterior $(\mathrm{C})$ and lateral (D) views. 

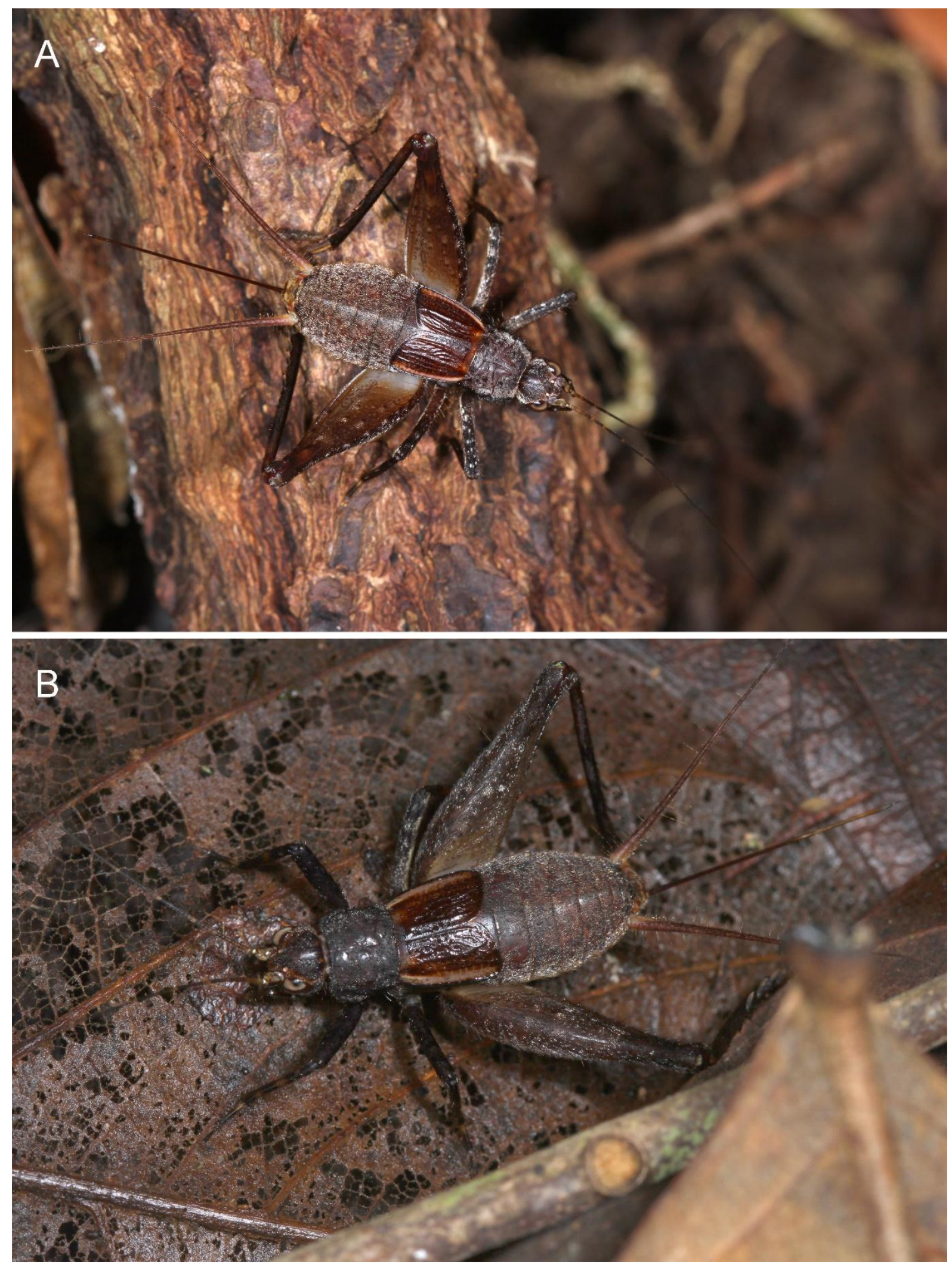

FIGURE 8. Terrozacla borneo Gorochov, 2014 females in natural environment in Belait. 

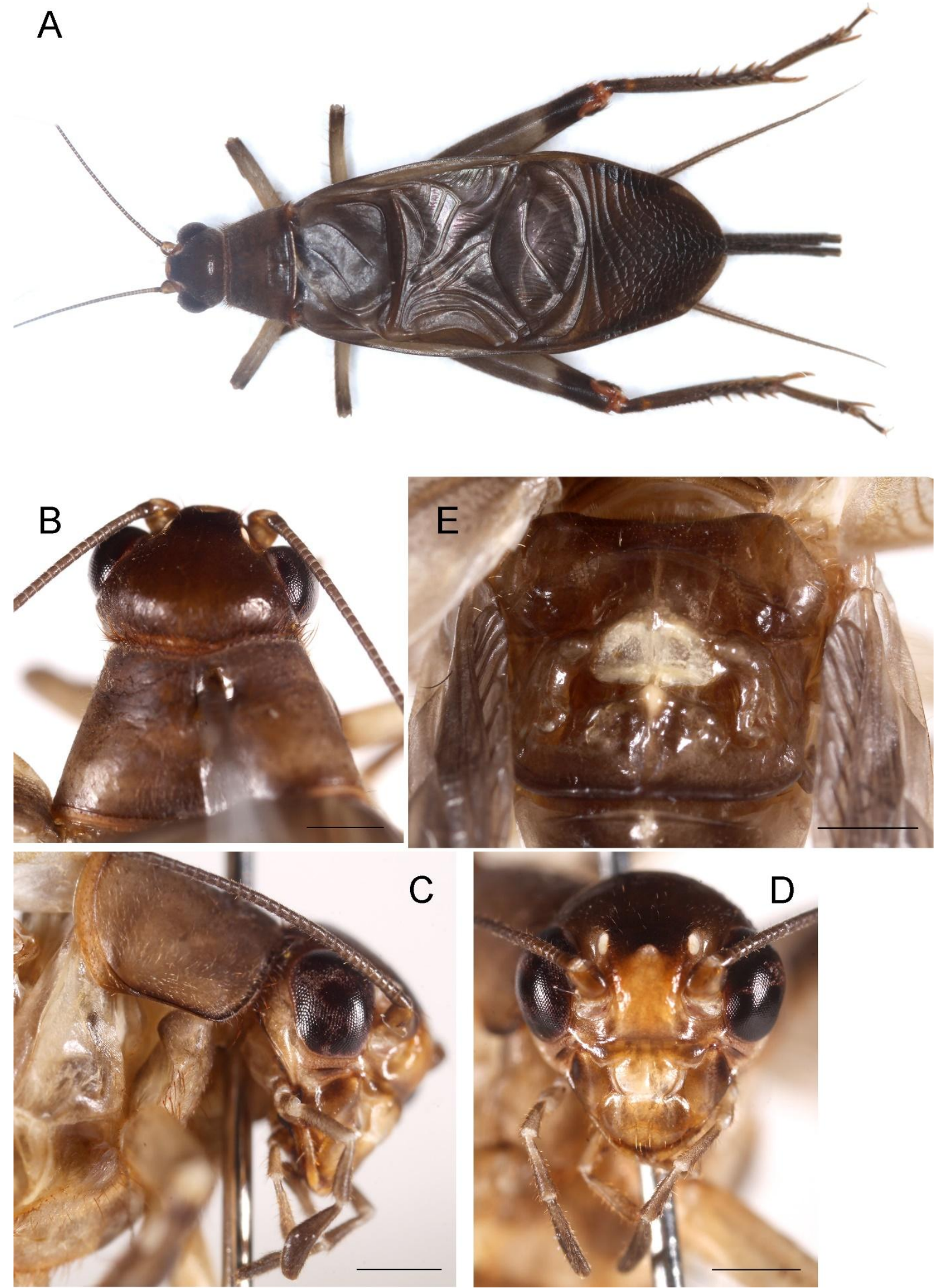

FIGURE 9. Itara (Bornitara) cuspis sp. nov. male holotype habitus in dorsal view (A), head and pronotum in dorsal (B) and lateral (C) views, face in anterior view (D) and metanotal gland in dorsal view (E). Scale bars: $1 \mathrm{~mm}$. 


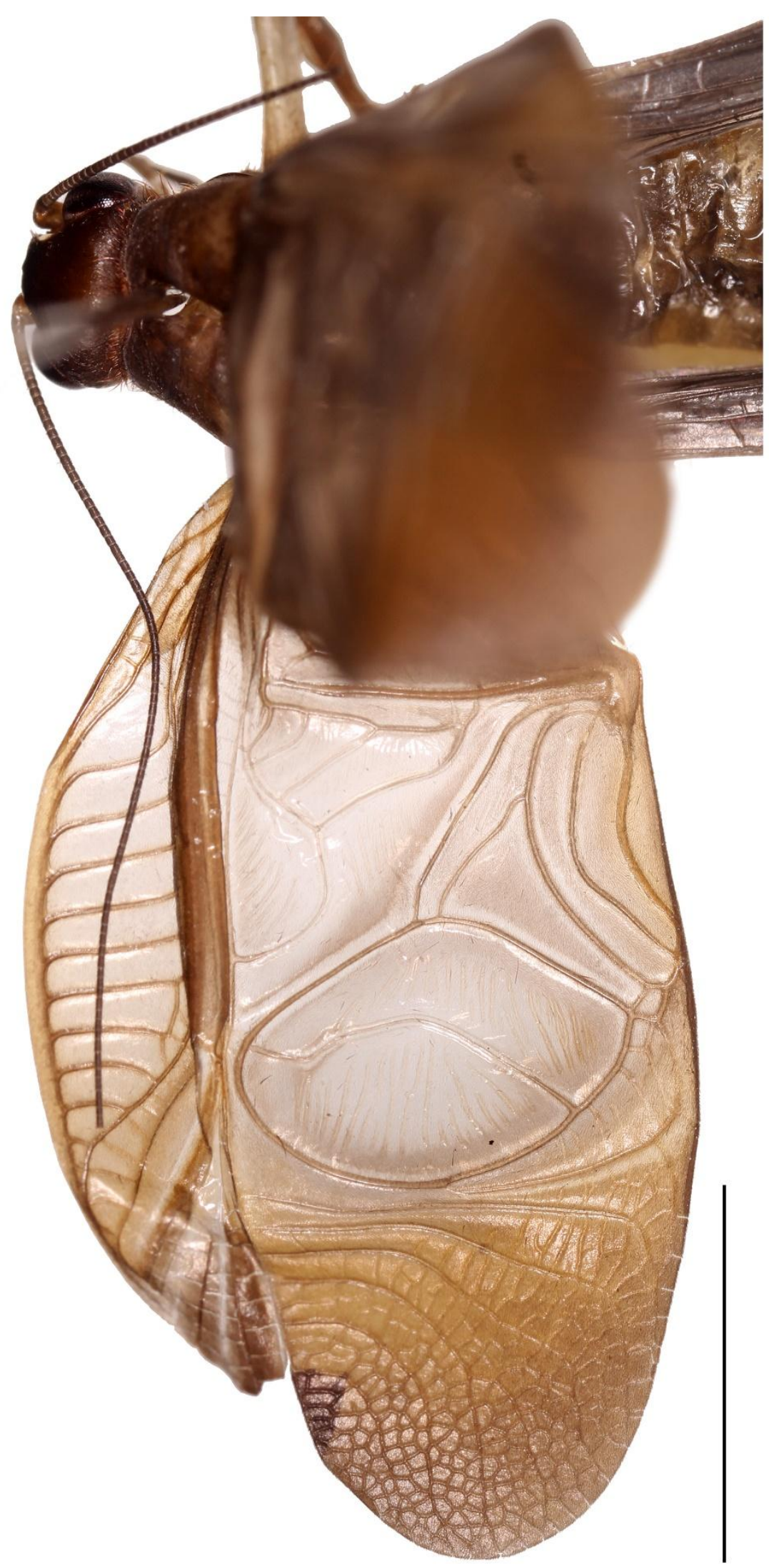

FIGURE 10. Itara (Bornitara) cuspis sp. nov. male holotype tegmen in dorsal view. Scale bar: 5 $\mathrm{mm}$. 


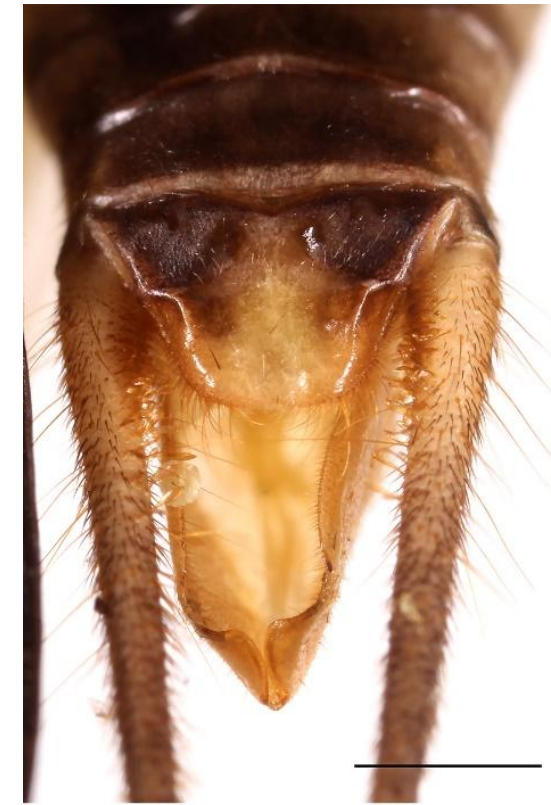

A

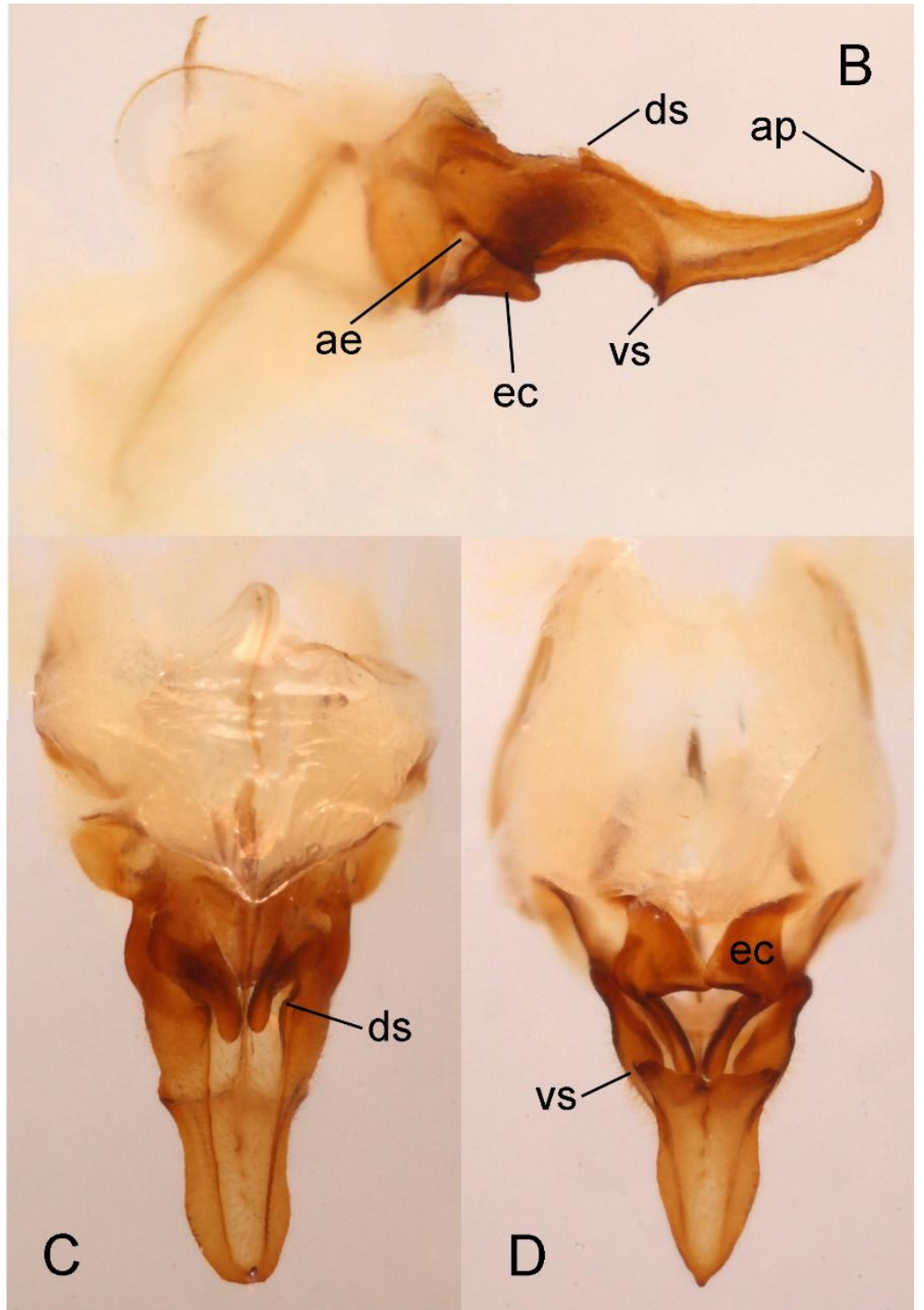

FIGURE 11. Itara (Bornitara) cuspis sp. nov. male holotype abdominal apex in dorsal view (A), genitalia in lateral (B), dorsal (C) and ventral (D) views. Scale bar: $1 \mathrm{~mm}$. 

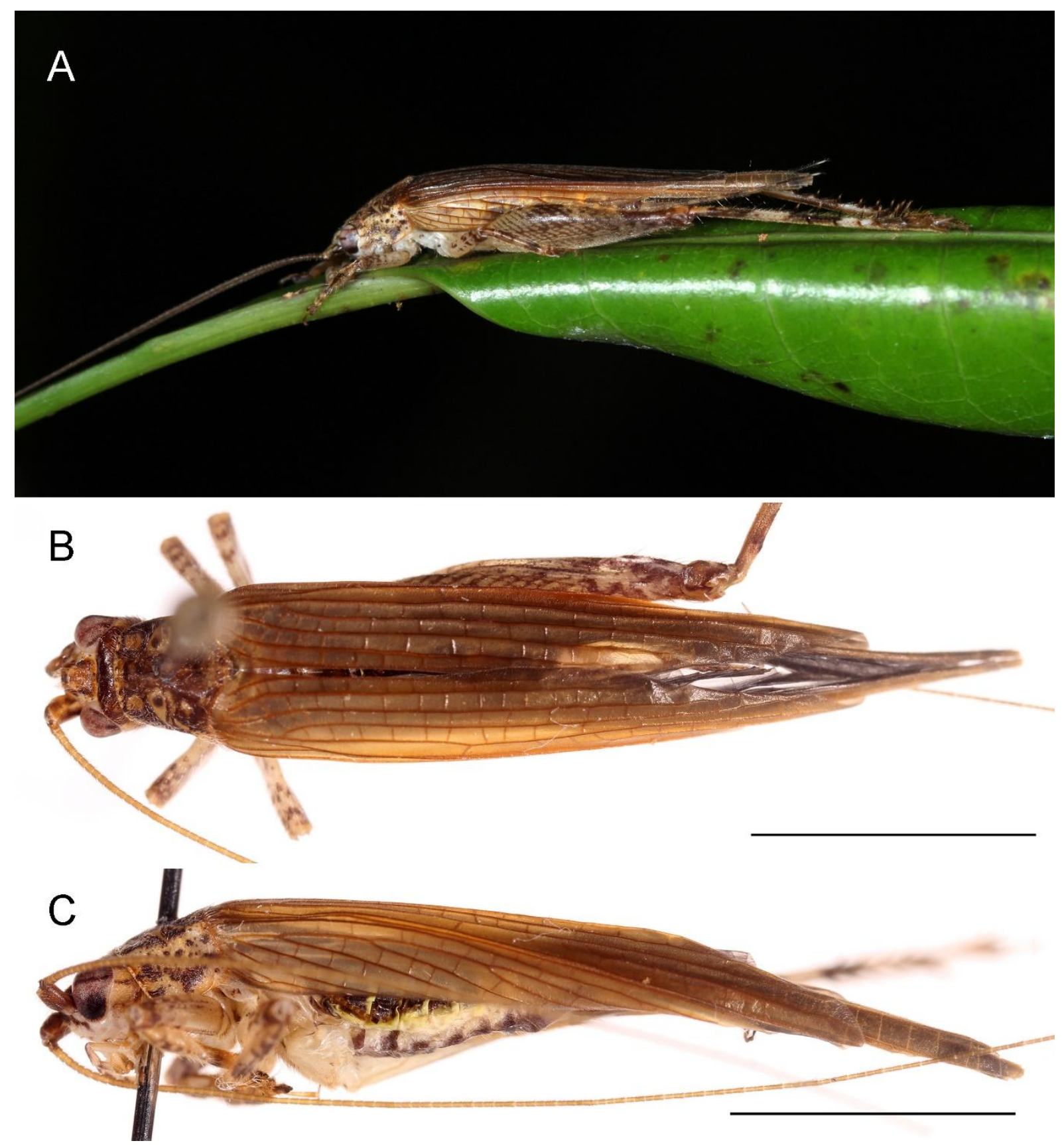

FIGURE 12. Aphonoides duri sp. nov. male holotype in natural environment (A), habitus in dorsal (B) and lateral (C) views. Scale bars: $5 \mathrm{~mm}$. 

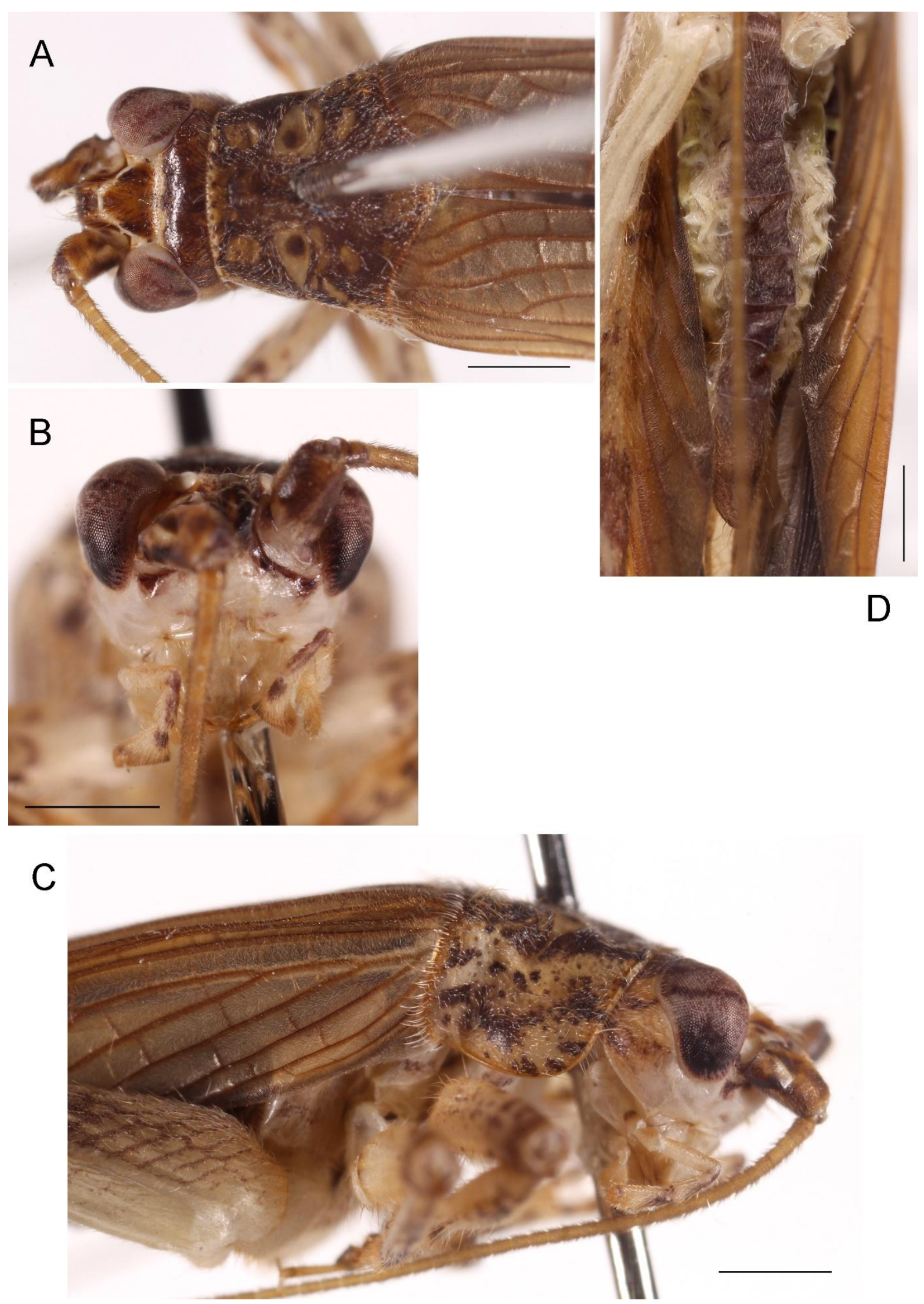

FIGURE 13. Aphonoides duri sp. nov. male holotype: head and pronotum in dorsal (A) and lateral (C) views, face in anterior view (B), abdomen in ventral view (D). Scale bars: $1 \mathrm{~mm}$. 
A

B

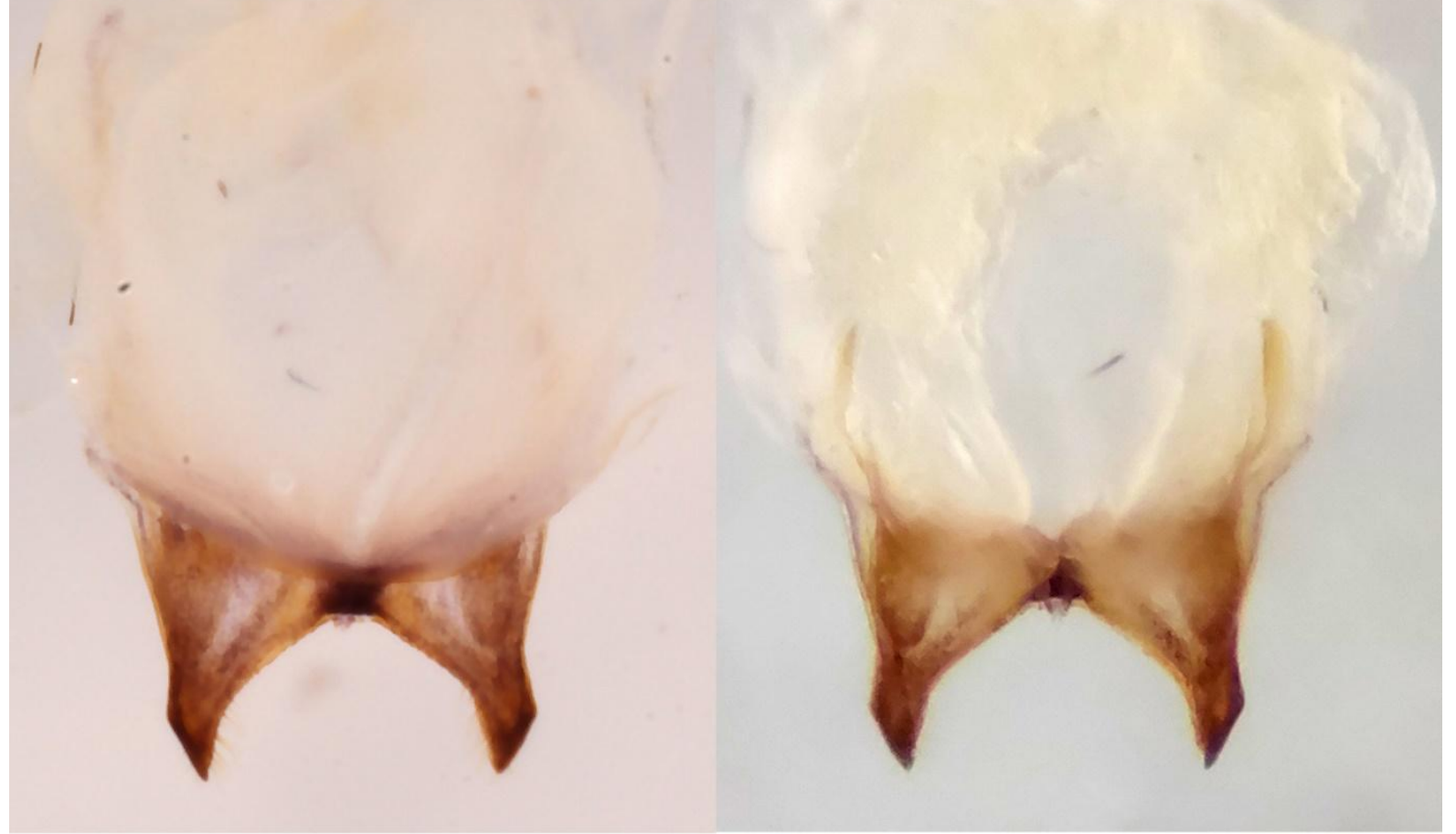

\section{D}

FIGURE 14. Aphonoides duri sp. nov. male genitalia in dorsal (A), ventral (B, C) and lateral (D) views. 


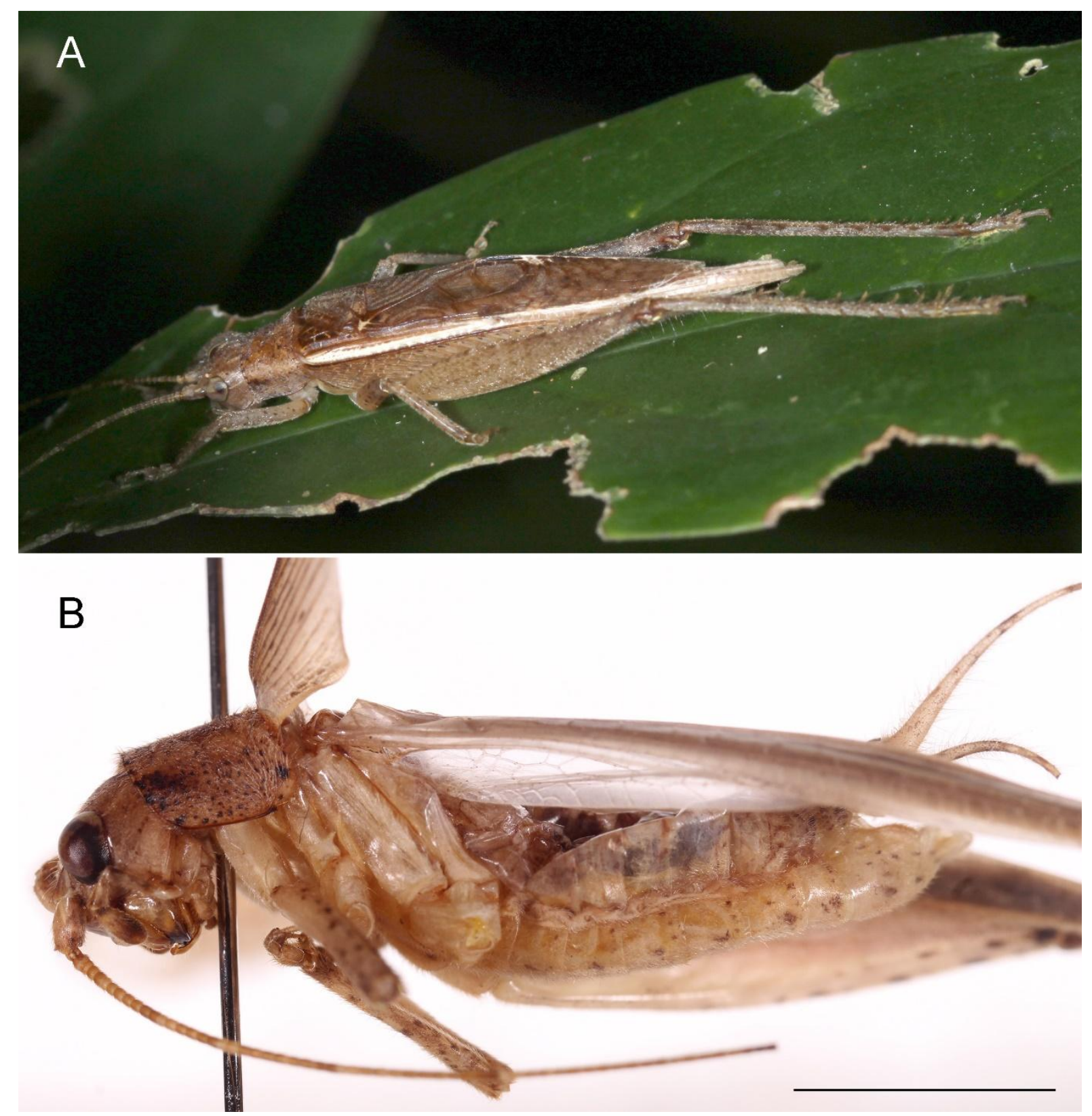

FIGURE 15. Varitrella (Cantotrella) suikei sp. nov. male holotype in natural environment (A), habitus in lateral (B) view. Scale bar: $5 \mathrm{~mm}$. 


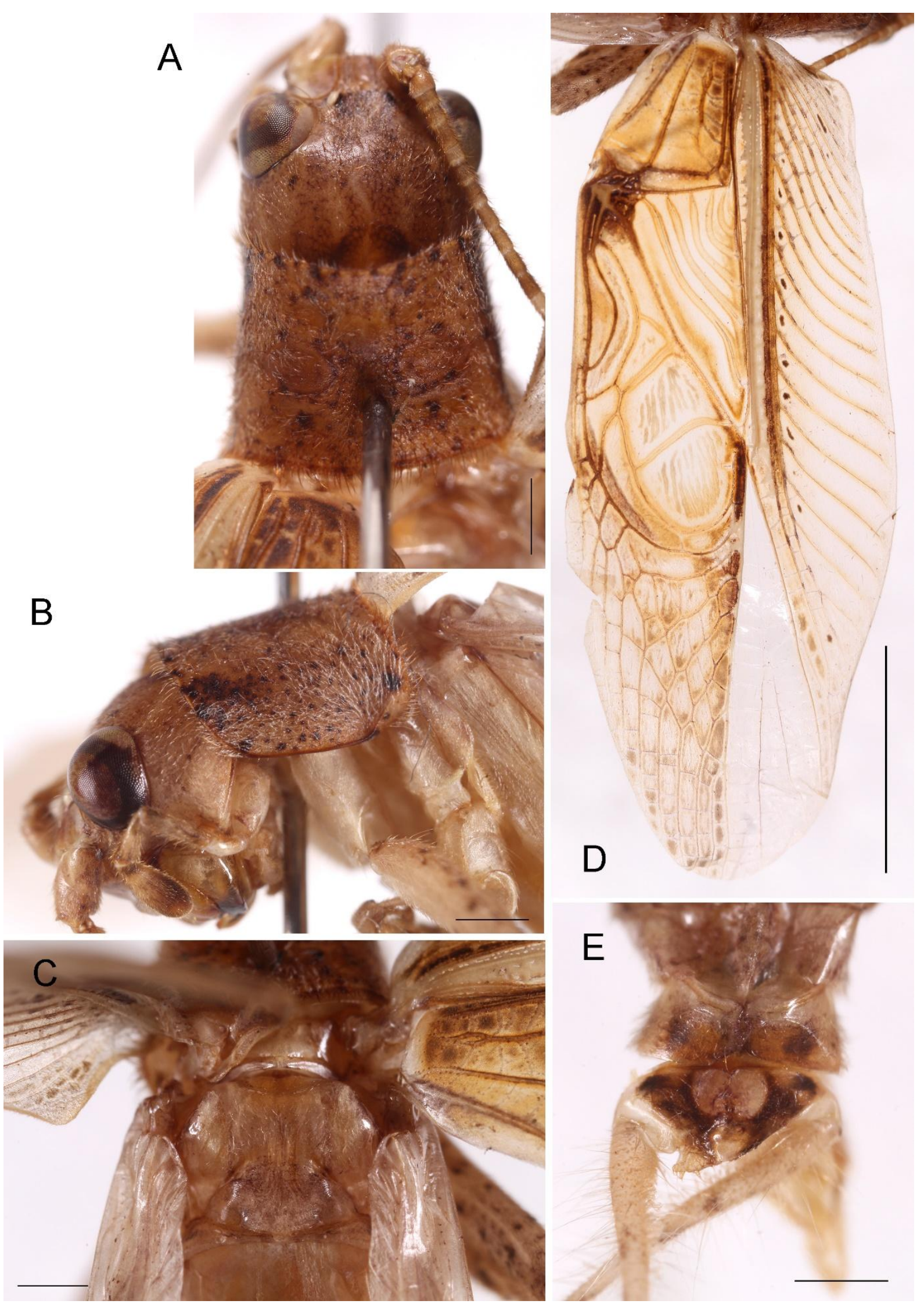

FIGURE 16. Varitrella (Cantotrella) suikei sp. nov. male holotype: head and pronotum in dorsal (A) and lateral (B) views, metanotal area in dorsal view (C), right tegmen in dorsal view (D) and abdominal apex in dorsal view (E). Scale bars: $5 \mathrm{~mm}$ (D), $1 \mathrm{~mm}$ (remaining). 


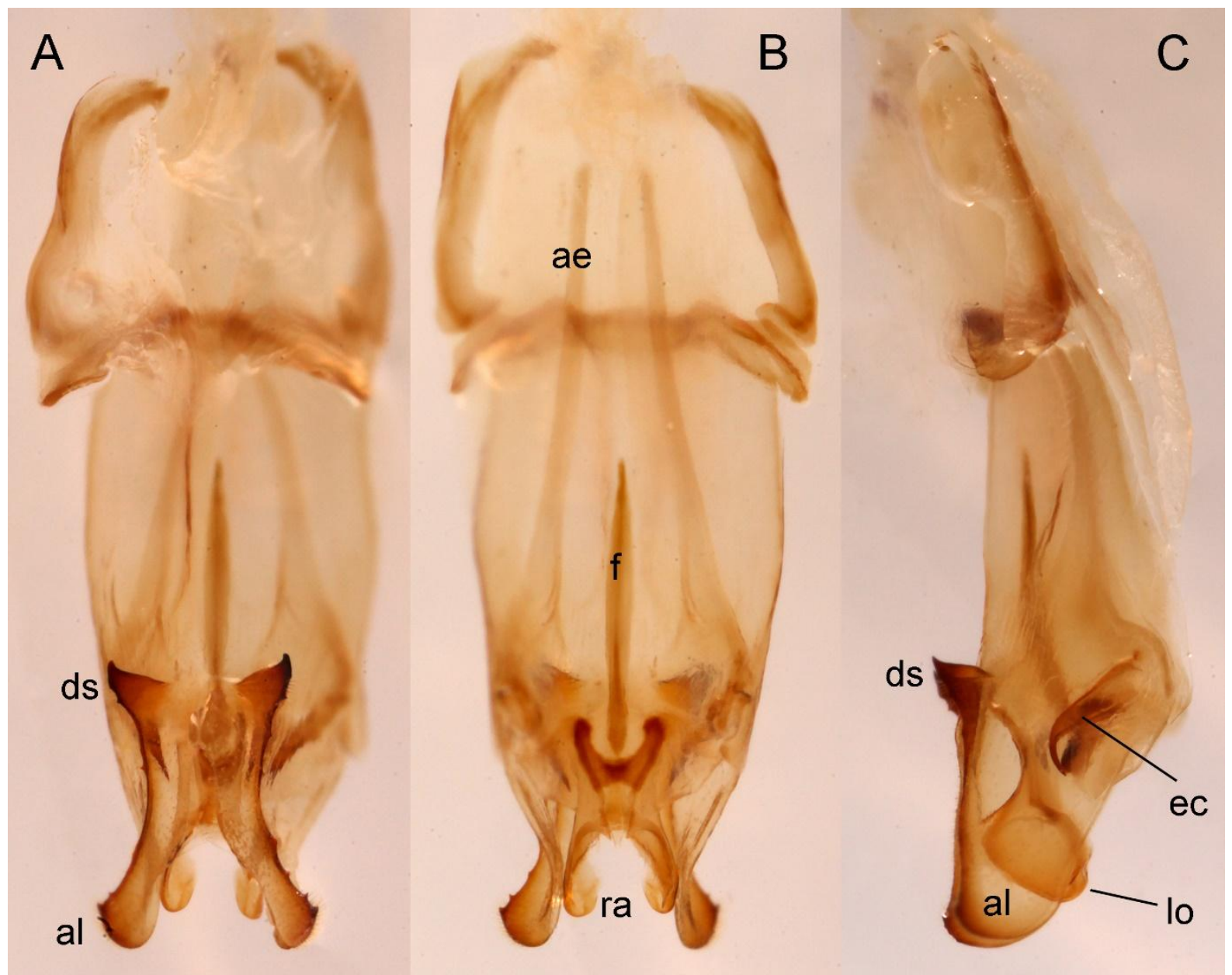

FIGURE 17. Varitrella (Cantotrella) suikei sp. nov. male holotype genitalia in dorsal (A), ventral (B) and lateral (C) views. 

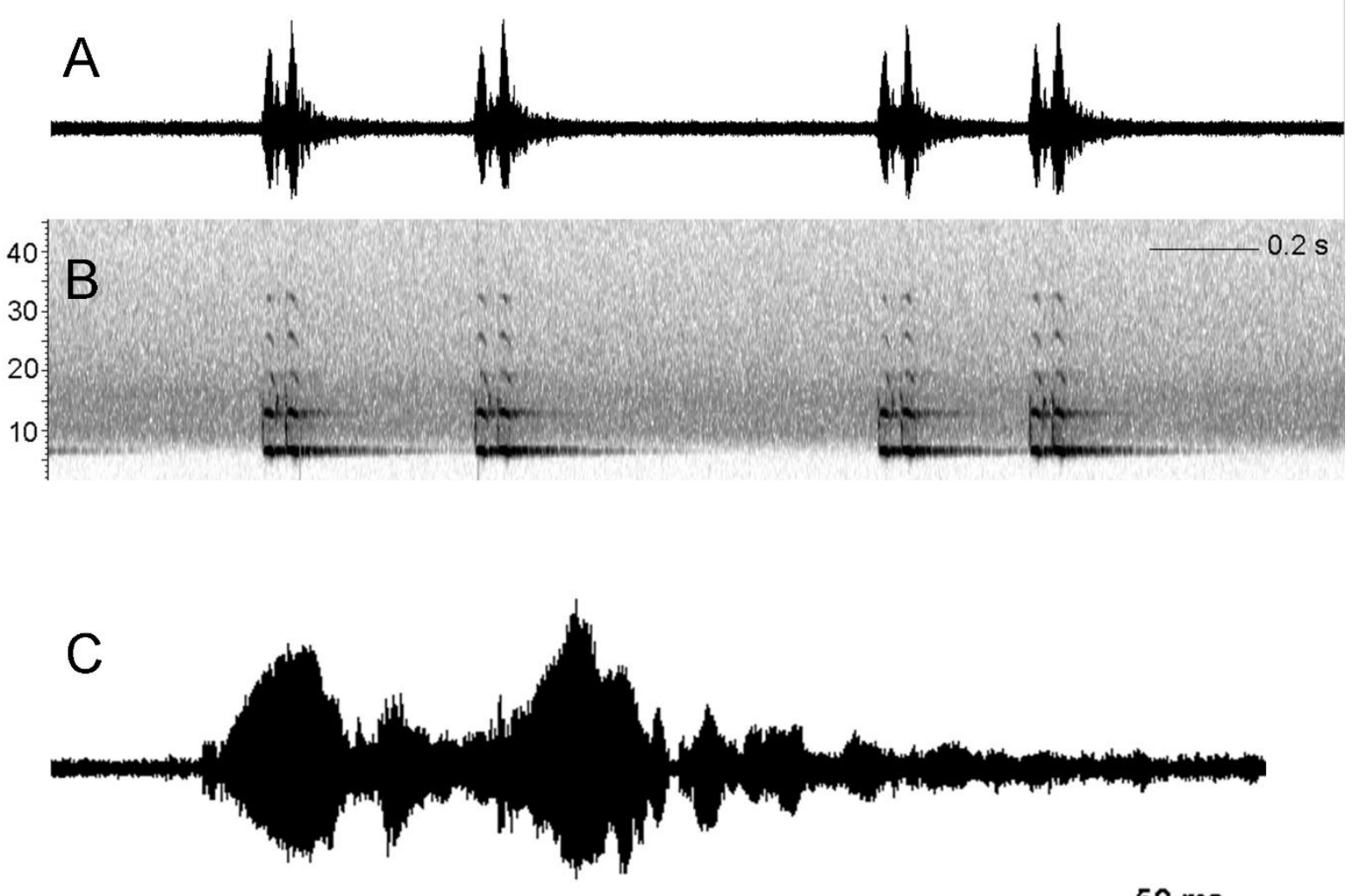

$50 \mathrm{~ms}$

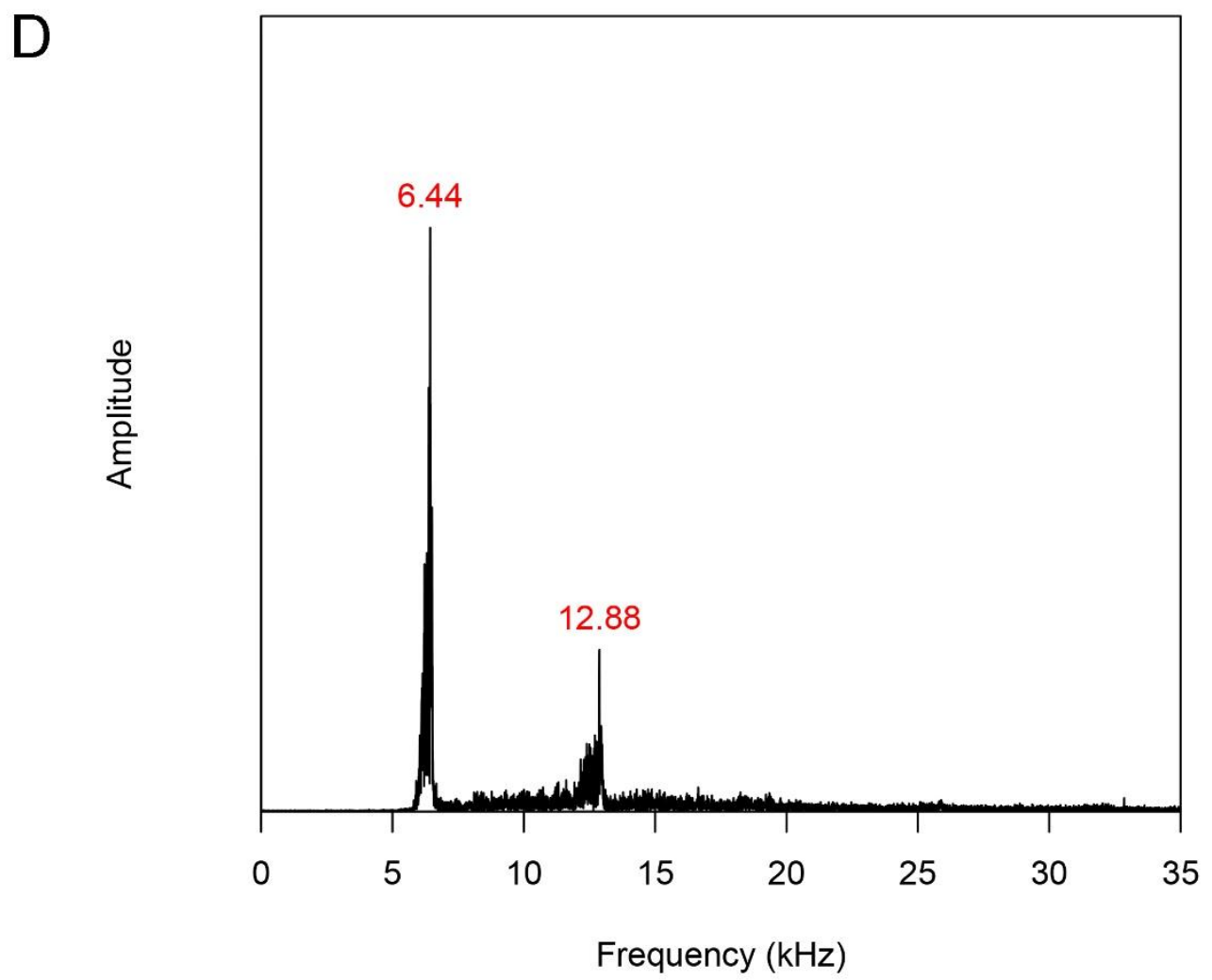

FIGURE 18. Varitrella (Cantotrella) suikei sp. nov. male holotype's calling song: oscillograms (A, C) and spectrogram (B) of four echemes (A, B) and one echeme (C) and power spectrum of one echeme (D). 